\title{
ZUR HILDENSAGE.
}

Die folgenden zeilen enthalten eine skizze; ohne die beweismasse, mithin ohne die beweisfuhrung zu erschöpfen, werden sie vielleicht den einen und anderen punct in ein richtigeres verhältnis der gesammtbetrachtung rücken.

I.

Die Hildensage im engsten sinne, das ist die sage von Hedin und Hildr, ist ostgermanisches eigentum; das bezeugt 1. der umstand, dass ihr das holmgangmotiv alle zeit eigentumlich blieb, 2. der persönliche inhalt, welcher dem stamm hild dauernd im norden anbaftete, als im westgermanischen bereits die vollkommene appellativierung $\mathrm{zu}$ der bedeutung kampf eingetreten war.

Ausfubhrliche uberlieferungen der sage besitzen wir erst etwa aus dem jahre 1200: eine islăndische der Snorra-Edda, eine dänische des Saxo Grammaticus. Beide berichten nach epischen quellen: der eine, der sagensammler, vielfach verworren, der andere, der chronist, mit mönchischem unverständnis, pseudohistorischen verknupfungen und romanfabulierenden schmuckzutaten; jeder unter ibnen von dem bestreben geleitet, alle ihm bekannten versionen zu verarbeiten und notdürftig in einklang zu setzen.

Der Isländer berichtet: König Högni (es scheint, in der vorlage localisiert in Dänemark ${ }^{1}$ )) hat eine tochter Hildr. In seiner abwesenheit (auf einer königsversammlung) heert in seinem lande kōnig Hedin, des Hjarrandi sohn (wie es scheint, i. d. v. localisiert in Norwegen), und entfuhrt seine tochter. Auf diese kunde eilt Högni ihm nach und erreicht ihn bei

1) จ. Klee, Z. Hilds. 6. 
den Orkneys: Hedin liegt vor der insel Haey, Högni legt offenbar an der andern seite an, und der holmgang kann beginnen. Zuvor geht Hildr zu ihrem vater und bietet ihm einen (!) balsschmuck zur sulhne, aber mit so höhnischen, herausfordernden worten, dass Högni im zorn erwidern muss; dann geht sie zu Hedin und vermeldet Högnis härte, der nichts von versöhnung wissen wolle. Trotzdem macht Hedin, als die heere schon zur schlacht aufgestellt sind, abermals, und diesmal persönlich, einen stlbnerersuch, den aber Högni mit einem: zu spät! abweist. Nachdem die epischen schlagverse aufeinander geprallt sind, klirren die streiche. Sie kämpfen den ganzen tag und gehen abends wider auf die schiffe. In der nacht, während sie schlafen, geht Hildr auf die insel und erweckt durch zauberei die leichen der gefallenen. Morgens erbeben sich die könige ton den schiffen und $\mathrm{kämpfen} \mathrm{weiter} \mathrm{und} \mathrm{(nun}$ erst!) ebenso jene gefallenen. Und so kämpfen sie tag fur tag. Und alle gefallenen mit ihrem gewaffen werden zu stein; wenn es aber tagt, stehen sie wider auf und kämpfen weiter. In den liedern aber heisse es, das werde so fortgehn bis zur gōtterdämmerung.

Der Isländer beruft sich auf mehrere lieder, und in der tat haben sich kreuzende uberlieferungen seinen bericht verwirrt. 1. Die kōnige kämpfen den ganzen tag und gehen abends zu den schiffen, am folgenden morgen kämpfen sie weiter und so bis an das ende der welt: das versteht man. Sämmtliche tote und ibre waffen werden abends zu stein, erheben sich aber allmorgendlich und kämpfen weiter: Das kann an jene uberlieferung angewachsen sein, wiewol es nach năchtlichem gespensterkampf schmeckt und offenbar an eine locale tradition anknupft, welche das groteske trummerfeld einer vulkanischen erruption mit den versteinten leichen des Hjadningenkampfes erklärte. Aber Hildr, die nachts die toten erweckt, damit dieselben morgens an der seite der lebenden weiter kămpfen, ist nicht einmal eine verschiebung, ist die misslungene einschweissung einer anderweitigen therlieferung. Jene liess die Hjadninge ihren kampf ewig fortkămpfen, diese liess sie sich gegenseitig erschlagen und von Hildr allnächtlich zu neuem kampfe erweckt werden. 2. Dem kampfe gehen zwei sulhnversuche voraus: der erste ein scheinversuch der blut- 
durstigen Hildr, der den zweck hat die suhne zu verhindern, der zweite ein ehrlicher versuch Hedins, der resultatlos verläuft, nicht etwa, weil Högni nunmehr zu schwer gereizt wäre, sondern weil der versuch zu spăt unternommen ist. Auch ohne diesen inneren widerspruch ist die häufung zweier versuche verdächtig; solche häufungen sind, wie ich in meinen Orendeluntersuchungen mehrfach darzutun hatte, stets ein zeichen veränderter tiberlieferung und in unserem speciellen fall eine nicht wider vorkommende wendung. Der verdacht einer contamination erbebt sich zur gewissheit, indem der Islãnder seinem prosabericht ziemlich moderne liedstrophen folgen lässt, deren pointe die scheinstuhne bildet. Dieselben berichten: die trugsinnende Hildr stillt die blutenden wanden, bietet ihrem vater Högni einen halsschmuck zur versöhnung, reizt aber zugleich die könige zum kampf; Högni schlägt die sthne ab, und der kampf beginnt auf's neue. Diese strophen sind so wenig die quelle von Snorris bericht wie die Völuspastrophen die quelle seiner baumeistersage; sie stellen einen ganz anderen sagenbestand dar: der suhneversuch, nur von Hildr angestellt, fällt in die mitte des kampfes, und Hildr stillt die blutenden wunden der Hjadninge. Der letztere zug, wie vielleicht auch der erstere, welcher die scheinsthne in die kampfpause verlegt ${ }^{1}$ ), verdankt seine entstehung dem eigentumlichen umstand, dass die strophen des angeblichen Bragi eine bildnerische darstellung der sage auf einem schild abschildern. Der bildner drängt den ganzen verlauf in eine momentsituation zusammen: zwischen beiden feindseligen heeren kniet Hildr, mit der einen hand zwar nicht tote erweckend aber wunden stillend, mit der anderen ihr halsband als stuhne dem zornig abwehrenden vater darbietend. Ob dem bildner bereits eine gleissnerei des slihneversuchs vorschwebte, mag fraglich sein; genug: dem dichter, der die schildscene besang, war dieser charakterzug sageneigentümlichkeit, und aus seinen strophen hat ihn Snorri, ganz analog seinem verfahren gelegentlich der baumeistersage, in seinen bericht vor Hedins

1) Obwol man andrerseits für die ursprïnglichkeit einer derartigen zeitfolge das 'zu spät' Högnis gegenüber dem zweiten versuch in das feld fuhren könnte, das episch mit dem typischen zwergenschwert begrindet wird. 
verspäteten suhneversuch (dem in epischen streitversen ausgefubrten hauptsttuck seiner hauptquelle) eingeschmuggelt.

Die gleissnerei der Hildr ist ein kind der uberlieferung. Die uberlieferung wusste von einem ewigen kampf um Hildr; vermenschlicht konnten die lebenden nicht ewig kämpfen, also kämpften die erschlagenen fort; und da nach dem bewusstsein einer zeit oder einer gegend oder einer Uberlieferung ${ }^{1}$ ) die toten ruhen, so wurde die altuberlieferte tatsache aus dem namen Hildr verstanden: Hildr war ein valkyrenname, die kampfesfreudigkeit der valkyrjen noch in der erinnerung lebendig - und so verzerrte sich die jubelnd dahinsturmende todesbotin Allvaters zu einer grinsenden furie, die aus mordlust tote nicht ruhen lässt, nachdem sie dieselben, vater und brăutigam, zu unversöhnlichem kampf aufeinandergehetzt hat. Und diese ganz unmythische auffassung. wird als urmythisch behandelt!

Der mythologe hat aus Snorris bericht zu entnehmen: 1. es fand ein ewiger, bez. sich in ewigkeit widerholender kampf um eine Hildr statt. 2. Begründet wird der kampf mit einer entfuhrung der Hildr aus den händen eines Högni, den die sage ihren vater nennt. Der entfuhrer heisst Hedin, des Hjarrandi sohn. 3. Der ewige kampf wird aufgefasst als ein fortkämpfen der erschlagenen, mithin ein seelenkampf. Dass die erschlagenen fortkämpfen, wird aus dem valkyrisch bekannten namen der umkämpften jungfrau heraus mit einer, der valkyrjenmythik sonst vollkommen fremden wendung motiviert. 4. Local wurde ein vulkanisches trummerfeld als kampfplatz der Hjadninge gedeutet. 5. Der uberlieferungsbestand enthält requisitorisch a) ein einer Hildr typisches halsband (als angebot der scheinsthne verwant), b) ein (in Hognis hănden befindliches) zwergenschwert, das nie in seine scheide zuruckkehrt, ohne blut gekostet $\mathrm{zu}$ haben: eine dichterische specificierung dieses in der mythisierenden heldensage altbeliebten wanderrequisites.

Sagengeschichtlich stellt sich Snorris therlieferung folgendermassen dar: In abwesenheit des Dănenkönigs Högni făllt der Norwegerkönig Hedin răuberisch in sein land ein und ent-

1) Ueber den anderwärts traditionellen seelenkampf s. $\mathbf{u}$. 
fuhrt dabei seine tochter Hildr. Högni erfährt das ereignis nicht bei sondern vor seiner rückkehr, verfolgt den räuber und holt ihn bei der Orkneyinsel Haey ein. Ein versöhnungsversuch scheitert an Högnis zorn, er erfolgt vor dem kampf oder in einer kampfpause, durch Hedin ehrlich oder durch Hildr zum schein. Der holmgang ergebt heer gegen heer; er dauert in ewigkeit, oder die kämpfer erschlagen sich, und die toten kämpfen fort; bezliglich: Hildr erweckt sie durch zauber zu immer neuem kampf.

Aus welchem grunde nun unternahm der Norweger jenen raubzug? Die alten, guten lieder schweigen echt episch; die motivierung gilt nichts, die situation alles. Aber der chronist Saxo weiss es: Hedin liebte Hildr, obwol er 'sie nie gesehen; und auch Sörla báttr hat eine antwort: eine blutdürstige valkyre hatte Hedin verhetzt.

Saxo berichtet: Höginus, ein riesischer, jähzorniger mann, ist rex Jutorum, also ein Dänenkönig. Hithinus, weit kleiner, aber sehr schön, ist ein norwegischer könig. Hithin und des Högin tochter Hilda entbrennen fur einander, noch ehe sie sich gesehn, und können nach einem romanmuster bei der ersten begegnung kein auge von einander verwenden. Ein gemeinsamer, glucklicher vikingzug stiftet $z$ wischen Hithin und Högin einen feierlichen freundschaftsbund: sie schliessen offenbar blutsbruderschaft; und Högin verlobt dem Hithin seine tochter. Aber das gute einvernehmen ist nicht von dauer: während einer abwesenheit wird Hithin bei Högin verläumdet, dass or vor der heiligen einsegnung die minne seiner tochter genossen hätte; es ist, als ob wir den Amicus und Amelius lăsen: unerlaubter liebesgenuss, zorn des vaters, gefahr des liebhabers; jetzt musste der getreue blutsbruder eingreifen aber der blutsbruder ist der beleidigte vater selbst: und aus dem motivierend eingeflochtenen freundschaftsroman kehrt die uberlieferung auf die ebene heerstrasse der Hildensage zurluck. Der zornige Högin eilt Hithin nach und greift ihn unversehens an, wird aber geschlagen. Darauf folgt ein vergeblicher suhneversuch (durch Frotho, dessen friede gebrochen ist), welcher scheitert, weil Högin seine tochter ungestum zuruckverlangt, und nunmehr findet der zweikampf der beiden gegner statt, in welchem Hithin schwer verwundet 
unterliegt, aber ob seiner schon zuvor pragmatisch eingefuhrten schönheit begnadigt wird. Trotzdem erneut sich nochmals der zweikampf: Hithin und Högin töten sich gegenseitig. Aber Hilda liebte ihren gatten so, dass sie allnächtlich durch zauberlieder die erschlagenen zu neuem kampf erweckte.

Allnächtlich also findet der ewige kampf statt, und er endet mit dem wechselmord Högins und Hithins. Dieser ergänzung der isländischen ubberlieferung gesellt sich eine weitere: Hithin und Högin heeren gemeinsam um des heerens willen, sie sind vikinger; und als viking wol hat der isländische Hedin Hildr entführt, sie heisst geradezu seine kriegsbeute. Der kampf der könige ist bei Saxo ein zweikampf, also ein regelrechter holmgang, wie er in Saxos uberlieferungen öfter um eine frau erfolgt. Der ausgang, dass beide gegner fallen, die nordische vulgata, ist verknupft mit einer anderen version, nach welcher Hithin unterlegen sein muss; seine begnadigung (vielleicht im anschluss an einen freundschaftsroman aus seiner schönheit motiviert) ist das bindeglied für die anknulpfung jenes zweiten, beiden teilen verhängnisvollen ausganges. Da nun für Saxo wie für die fabulierer aller zeiten der guten dinge stets drei sein mussen (eines der unbewussten grundgesetze der composition), verwandelt er den ersten kampf in zwei kämpfe, wol in anschluss an eine tiberliefernng, nach welcher der versöhnungsversuch in die kampfpause fiel. Ein ursprunglicher zug taucht wol in Högins betonter riesischer erscheinung auf; dagegen läge es nahe seine zornmutigkeit fur eine pragmatische voraufnahme seines unversöhnlichen verhaltens zu nehmen, wenn nicht Sörla Dáttr und Kudrun eine ähnliche charakterauffassung betätigten. $\mathrm{Ob}$ das blutsbrudermotiv in dem roman schmarozt und dem Saxo die motivierende verwendung des freundschaftsromanes eingegeben hat, oder ob es selbst der letzteren seine einflechtung verdankt, ist nicht eindeutig zu entscheiden; fur die erstere annahme spricht die rolle, welche das motiv in S. D. spielt.

S. D. ist eine, um ein volles jahrhundert jüngere, isländische uberlieferung, mythisch uberladen und aus christlicher tendenz in das frevelhafte und gespenstische verzogen. Odin entfuhrt der Freya das von ihr in schmutziger weise gewonnene hals- 
band Brinsingamen und gibt es ibr zurtick gegen die verpflichtung, zwei könige zu unversöhnlichem kampf zu verhetzen, von dem sie erst - das christentum erlösen wird. Diese könige sind der Däne Högni, dem zwanzig könige folgen, und Hjarrandis sohn Hedin, der auch uber zwanzig könige gebietet. Der letztere herrscht im Sarazenenland, dem Orient, dem osten; als er einst im winter in den wald geht, findet er auf einem stuble sitzend eine schöne frau Göndul und fragt sie, ob sie seinesgleichen kenne; sie nennt ihm Högni, und sofort begehrt Hedin dessen macht zu erproben. Im fruhling bricht er auf, und da der erzähler weiss, dass der weg ein weiter ist, so reist Hedin sommer und winter, aber just im fruhjahr erscheint er bei Högni. Der freundlichen aufnahme folgen stärkeproben, als wäre von Thor und Hymir die rede. Der ausgang ist der beste: die ebenburtigen helden schliessen blutsbruderschaft. Während nun Högni einmal im krieg ist und Hedin sein reich hutet, findet letzterer im wald jene Göndul; sie reicht ihm einen trunk, nach dessen genuss er alles vergessen haben soll, befragt ihn aber trotzdem tuber seine stärkeproben mit Högni und erhält auch den ganz sachkundigen bericht ihrer ebenburtigkeit. Diese ebenburtigkeit will sie nicht gelten lassen: Högni sei ihm durch den besitz eines edlen weibes uberlegen, und als Hedin dem geistreichen einwurf mit der einfachen lösung begegnet, er werde bei Högni um dessen tochter werben, wird die pointe des berichtes durch die ebenso geistreiche erwiderung gerettet, das sei Hedins nicht wurdig: entfuhren mulsse or das mådchen und die mutter unter seinem schiffe zerquetschen. Und Hedin, der ja alles (will sagen: seine blutsbruderschaft) vergessen hat; nimmt mutter und tochter und, als viking, auch alle erfindlichen schătze zu seinem schiff. Vergebens bittet ihn Hildr von der entfuhrung abzustehn, da er sie durch werbung erhalten könne, vergebens fleht sie wenigstens um das leben der mutter, da sonst jede versöhnung ausgeschlossen sei; trotz dieser erneuten vaticinatio ex eventu wird die mutter mit der vorgefassten grausamkeit getötet. Man sollte denken, dass Hedin nunmehr der boden unter den fussen brenne; nichtsdestoweniger sucht er Göndul von neuem auf, empfăngt einen neuen trunk, entschlät, sieht im erwachen, wol nach irgend einem muster, 
die hexe schwarz und gespenstisch entschweben, erinnert sich wider an 'alles' und fluchtet in verzweiflung, aber nicht ohne Hildr. Als Högni bei seiner ruckkunft erfährt, wie sein blutsfreund bei ihm geheert und gehaust, folgt er ihm zornig und ereilt ihn bei der insel Há. Hedin grusst ihn und will ihn versöhnen, aber der schatten der königin steht zwischen ihnen. Hedin schlägt zweikampf vor, aber die beiderseitigen heere verlangen ihren anteil. So beginnt der holmgang und dauert fort und fort, denn ob sie sich bis zu den schultern zerspalten, stehen sie wider auf und kämpfen weiter, während Hildr teilnahmlos zuschaut. So geht es uber hundert jahr, bis des christlichen Olaf ritter Ivar Ljómi, dessen name schon wie der tag leuchtet, dem nächtlichen gespensterspuk, gemäss jener unvermeidlichen vaticinatio ex eventu, ein ende macht.

Die vaticinatio ex eventu ist das charakteristische gepräge der verunglückten versuche des erzählers, seinem bericht das ausseben eines pragmatisch verknlupften verlaufs zu geben; sie ist das merkmal seiner zutaten. Seine vorlage begrundete Högnis unversöhnlichkeit mit dem grausamen ende seiner gattin: in dem bericht ist dieses ende eine voraus beschlossene und angeratene grausamkeit, auf dass die versöhnung unmöglich werde. Die königin stirbt, indem das räuberschiff uber ihren körper flott gemacht wird (es war also in der vorlage nicht eben erst gekommen): der bericht fuhrt das schiff schon in der ausfahrt Hedins mit namen ein, wăhrend es bei Hōgnis rückkunft plötzlich als ein ihm geraubtes gut erscheint. Nach der auffassung des erzählers ist die ganze entfuhrung eigentlich eine unnutze rohheit, da räuber und beraubter blutsfreunde sind und ein wort genugt bätte eine verlobung in ebren zu stiften; darum durfte Hedin nichts mehr von der freundschaft wissen: er batte à là Sigfrid einen vergessenheitstrank getrunken; und es erscheint als eine recht unnlitze grausamkeit der valkyre, dass sie, nachdem der tod der mutter die versöhnung im voraus vereitelt hat, mit einem gegenmittel den armen Hedin der erinnerung zurtlck und der verzweiflung anheimgibt. So wird von seinen schultern der treubruch abgewälzt, der in der vorlage auf Yhnen gelastet zu haben scheint. Aus der vorlage hat der erzähler diese kindereien sicher nicht 
entnommen; doch mag ihn eine tradition geleitet haben, welche von einer. valkyrischen aufreizung zu unausweichlichem kampfe die erinnerung bewahrte. Seine Hildr hat offenbar nichts von blutdurst und kampfesfreude; sie ist die frevelhaft von dem treulosen blutsbruder entfuhrte jungfrau, welche stumm dem um sie entbrannten kampfe beiwohnt, einem ewigen totenkampfe mit einem stich in das gespenstisch colossale. Auch in dem holmgang verschweisst der erzähler zwei wendungen, den zweikampf und den heereskampf. Ob die Olaflösung schon der vorlage anhaftete, ist nicht zu sagen, während die plumpe anknupfung an das Brisingamenmotiv, nach dem merkmal der vat. ex ev. zu urteilen, dem geistreichen einfuhrer der Göndul zur last fällt. Hinwiderum mag der im osten zur winterszeit weilende und mit dem lenz bei Högni erscheinende Hedin eigentum der vorlage sein; vielleicht weisen die sich anschliessenden stärkeproben (zugleich das angebliche motiv der fahrt) auf einflechtung von motiven des Thorkreises; es wäre dies scheinbar das erste mal, dass dem Hildenkreis jahreszeitliche elemente zugewachsen wären. Scheinbar das erste mal.

Ueberschlagen wir unser sagengeschichtliches ergebnis. 1. Isländische uberlieferungen, aufgezeichnet 12/13. jh.: in abwesenheit des Dänenkönigs Högni heert der norwegische viking Hedin in seinem reich und entfuhrt seine tochter Hildr als kriegsbeute. Högni, in der fremde benachrichtigt, ereilt den räuber bei der Orkneyinsel Haey. Vergeblicher versōhnungsversuch vor dem kampf oder in der kampfpause, ehrlich seitens des entfuhrers oder gleissnerisch seitens der entfuhrten, die dann als valkyre gedacht ist; unversöhnlichkeit Högnis, holmgang heer gegen heer; entweder kämpfen sie ewig, oder sie erschlagen sich gegenseitig, und die toten kämpfen weiter, bezliglich: Hildr erweckt sie allnăchtlich durch zauberlieder zum totenkampf.

2. Dänische aberlieferungen, aufgez. 12./13. jh.: der Norwegerkönig Hithin entführt des Dänenkönigs Högin tochter Hilda, Högin eilt ihm nach, ein versöhnungsversuch (seitens eines dritten), vielleicht in eine kampfpause fallend, scheitert an Högins zorn; der kampf ist ein zweikampf, entweder fällt Hithin, oder beide töten sich gegenseitig und werden allnächt- 
lich von Hilda durch zauberlieder zu neuem kampf erweckt. In der ersten fassung wendet sich bereits die gerechtigkeit gegen den entfuhrer. Vielleicht sind Högin und Hithin blutsfreunde. Als grund der entfuhrung gibt Saxo liebe an.

3. Isländische uberlieferungen, aufgez. c. 13/14. jh.: Hedin (aus dem Ostland) entfuhrt des Dänenkönig Högni tochter Hildr während seiner abwesenheit im kriege; es scheint, dass sie ungern folgt, und dass ihre mutter grausam getōtet wird. Högni, bei seiner rückkehr unterrichtet, ereilt den räuber bei der insel Há (gleich Haey), der versöhnungsversuch Hedins vor der schlacht scheitert an Högnis zorn; der kampf ist entweder zweikampf oder heereskampf; er dauert in ewigkeit als fortkampf der toten ohne erweckung durch Hildr. Möglicherweise bewog den erzähler eine tradition von valkyrisch blutdurstiger mitwirkung zu der einfuhrung einer anreizenden valkyre. Die gerechtigkeit ist gegen den entfuhrer. Es scheint, dass derselbe ein blutsfreund des beraubten und in dessen abwesenheit der hüter seines reiches und hauses war.

Dieser uberlieferungsschatz erfährt eine wertvolle bereicherung durch eine ballade, welche im 18. $\mathrm{jb}$. von Low aufgezeichnet wurde. Sie ist ein tanzlied, von bauern gesungen auf der Shetlandsinsel Fula unweit den Orkneys in der damals aussterbenden norsischen mundart. Schon Low wusste sie nicht zu entziffern, liess sich aber ihren inhalt folgendermassen erzählen: Hiluge (d. i. Illughi, der bössinnige), ein vornehmer am norwegischen hofe, freit um die königstochter Hildina; der vater ist geneigt, die tochter weist ihn ab. Während der böse und der vater im krieg sind (auf einer vikingfahrt), landet der jarl der Orkney in Norwegen (als viking?), sieht Hildina, liebt sie, findet gegenliebe und entflieht mit ihr. Die beiden heimkehrenden verfolgen ihn zu seinen Orkneys; ein versöhnungsversuch, den der jarl auf Hildinas bitten bei dem vater unternimmt, hat erfolg; während er aber eilt Hildina die freudenkunde zu bringen, stimmt der böse den vater wider um, und in dem holmgang erschlägt den jarl - nicht der vater, sondern der nebenbuhler. Folgt Hildinas rache.

Die versöhnung mit widerruf und die nichtbeteiligung des verfolgenden vaters an dem entscheidungskampf weisen auf eine vermischte laberlieferung. Deutlich ist als grundlage die 
vulgata zu erkennen: ein viking entfuhrt die tochter eines kriegerisoh abwesenden königs, wird von ihm nach seiner ruckkehr verfolgt, auf den Orkneys ereilt und macht einen versōhnungsversuch. Hier setzt das neue motiv ein: die jungfrau hatte zwei bewerber, der eine der begthnstigte, der andere der abgewiesene; von jenem lässt sie sich entfuhren, dieser erschlägt den entfuhrer im holmgang. Der holmgang um die jungfrau hat ein im norden in vielen uberlieferungen ${ }^{1}$ ) auftauchendes, offenbar zu einer gewissen zeit beliebtes motiv associiert: den holmgang der nebenbubler. Der verfolgende nebenbuhler gesellt sich notwendig dem verfolgenden vater: er wird der von ihm begunstigte bewerber, vielleicht gar sein blutsbruder. Naturlich druckt der neue verfolger auf den alten; er wird der rächer, der andere ist versöhnlicher natur. Dass der entfuhrer fällt, ist keine neue wendung; in gewissen uberlieferungen war die gerechtigkeit gegen ihn. Dass in dem gegebenen fall der entfuhrer als der geliebte, der gute anfgefasst wird, der verfolger und uberwinder als der bōse, verschmähte mörder, ist eine folge des ausganges; denn das darf niemals von dem psychologen des romans ubersehen werden: sobald der ausgang die pointe enthält (der regelrechte fall), ist er der die fabulierung vor allen anderen beherrschende ktunstlerische punkt. Der ausgang des balladenromans aber ist Hildinas rache. Es ist so lehrreich wie interessant zu beobachten, wie sich der gerechtigkeitssinn zwar auf seiten des beleidigten vaters stellt, die epische sympathie aber auf seiten des entfuhrers: er ist der geliebte, blutige rache suhnt seinen tod. Bei einer entgegengesetzten pointierung, welche den entfuhrer als den ungeliebten vergewaltiger hinstellte, wendete sich naturlich die volle antipathie gegen ihn und liesse ihn mit wollust $\mathrm{zu}$ grunde gehn.

$\mathrm{Zu}$ bemerken ist noch an dieser uberlieferung, dass sie das motiv des holmgangs zu einem kampf in des entfübrers heimat verschoben hat.

Das nebenbublermotiv erscheint zum zweiten mal in einer complicierten uberlieferung, welche zu anfang des dreizehnten

1) Es ist auch die schablonenform, in welche Saxo seine Baldrsage presste. 
jahrhunderts auf polnischem boden aufgezeichnet wurde und nach namengebung und ausgang der Walthersage zugehört. Walther (Walgierz) der starke (manu fortis), zu Cracau ansässig, weilt am hofe des Frankenkönigs, dessen tochter Helgunda von einem alemanischen königssohne geliebt wird und seine werbung begunstigt. Walther besticht den turmwächter, dass er ihn nachts auf die burgzinne lässt, und singt dort so schön, dass Helgunda dem wächter durch drohungen den namen des sängers abnōtigt. Sie entbrennt in liebe zu ihm und lässt ihn in ihre kammer; der gekränkte Alemane zieht sich zurtick und bewacht die Rheinzölle. Als nun das liebespaar flieht und uber den Rhein setzen will, wird ihm eine mark goldes von den fährleuten abverlangt. Walther bezablt das gold, das beinah nach einer subnesumme schmeckt, und als man ihn trotzdem nicht therfährt, nimmt er Helgunda hinter sich auf das ross (jetzt erst?) und sprengt mit einem kuhnen satz ther den strom. Da ertönt hinter den fluchtlingen die stimme des Alemanen: Treuloser, du entfuhrst die kōnigstochter und setzest uber ohne zu zollen? Der kampf entscheide, wem die jungfrau und des besiegers ross und waffen verbleiben! Nach Walthers replik erfolgt der $\mathrm{zweikampf}$ in charakteristischer altertumlichkeit: anfänglich hat der Alemane Helgunda im gesicht und ist im vorteil; sobald der zuruckweichende Walther sie vor augen bekommt, verdoppeln sich seine krăfte, und er erschlägt den gegner. Der ausgang ist offenbar einer trefflichen vorlage nacherzählt.

$\mathrm{Zu}$ der Walthersage stimmen in dieser therlieferung die namen der liebenden, ibre flucht auf einem ross, das unterhandeln mit fährleuten am Rhein, der kampf jenseits des Rheines und sein schliesslicher ausgang. Auch, dass der grund der entfuhrung liebe sei. Nicht in die Walthersage gehört schon die art, wie der entfuhrer die liebe der jungfrau erwirbt: durch gesang. Auch in ihrer entstellten ${ }^{1}$ ) gestalt stimmt die uberlieferung dieser werbung mit der Horantepisode der Kudrun dermassen in den details uberein, dass man geneigt wäre jene einfach aus dieser abzuleiten, wenn sie nicht auch

1) Die bestechung verschafft dem sänger wol nicht zutritt zu der zinne sondern der kemenate. 
in der deutschen Hildenentfuhrung ein fremdes element ausmachte ( schmelzung in disparate uberlieferungen ibre ursprungliche selbstanndigkeit bezeugte. Widerum ein drittes element bildet das nebenbuhlermotiv. Nicht der vater der geraubten verfolgt den räuber sondern ein liebhaber (die vorlage sagt: ein ursprunglich begunstigter liebhaber; die begunstigung durch die tochter ist vielleicht aus dem in der fabel begrtundeten gunstverhältnis zu dem vater entstellt); der verfolgte ist Walther, folglich nach der durchgedrungenen wendnng der Walthersage erschlãgt er den verfolger. $\mathrm{Zu}$ bemerken ist, dass die fliehenden nicht im rasten sondern im reiten ereilt werden, dass der kampf um die jungfrau stattindet und ein einziger zweikampf ist.

Nochmals erscheint der nebenbuhler in den nordischen Hillaballaden, welche schon durch ihre namengebung sich als deutsches spielmannswandergut kennzeichnen. Hilla wird (schwedisch) an ihres vaters hof von sieben rittern bewacht; zwei bedienen sie tãglich; der eine, Magnus, umbuhlt sie unerhört, von dem anderen, Hillebrand, lässt sie sich entführen. Verfolger sind nicht die wächter noch der nebenbuhler sondern vater und brider. Die fluchtlinge rasten gerade im walde, sein haupt ruht auf ihrem schooss, da hört sie die rosshufe der verfolger und weckt ihn: es ist, als ob wir den oberdeutschen Walther lăsen. Hillebrand) erschlägt alle verfolger bis auf den jungsten bruder; in ihrer angst um diesen ruft Hilla den Hillebrand trotz seiner warnung bei namen, und durchbohrt sturzt or auf den grund. In Ribolt und Goldburg (soll heissen Herburt und Hildburg?) hat der vater die tochter einem ungeliebten mann verlobt, und sie entflieht mit dem geliebten. Der ungeliebte ist unter den verfolgern. Ribolt erschlägt alle verfolger, gelangt mit Goldburg an's ziel - und erliegt der todeswunde, welche er empfieng, als ihn Goldburg trotz seiner warnung aus angst um den goldgelockten bruder bei namen rief. Man sieht deutlich die mischung zweier versionen: nach der einen, der deutschen Walthervulgata, erschlägt der entfuhrer die verfolger, nach der anderen, die sich nordischen tiberlieferungen zu năhern scheint, wird er erschlagen. Die letztere wendung ist durchgedrungen und hat sich zu einem kleinen 
busseroman der unfolgsamen kleinen Hilla, welche sich entfubren liess, fortgebildet: die entfuhrung wird verurteilt. Der nebenbuhler wie der, wol ebenfalls dem nordischen Hildenkreis entnommene ${ }^{1}$ ), verfolgende vater spielen keine rolle gegenuber dem siegreichen brlidermotiv, das so recht in der nordischen balladenwelt zu hause ist. Die ursprunglichen verfolger waren wol die wächter der Hilla im schwedischen lied, deren anzahl in einem, leider von später pointierung beherrschten lied auf zwölf bemessen wird.

Die rastsituation des schwedischen liedes verweist die gruppe in unmittelbare beziehung zu dem deutschen Walther; die abweichungen erklären sich nicht so sehr aus den unbedeutenden angleichungen an die nordische bildensippe als durch die fortbildende kraft des neuangetretenen balladenbrudermotirs, das nach einem psychologischen grundgesetz der fabulierung eine kette neuer motive ausgelōst hat. Mit den verfolgenden brtidern tritt.der zum typus ausgebildete geliebte goldlockige jungste in sein recht: er soll nicht sterben! mit ihm das motiv der verbotenen namennennung, mit diesem das bōse ende: die zurllckfuhrung Hillas und ihre bestrafung (die zur pointe des ganzen wird: sie wird verkauft) - und was kommt. schliesslich heraus? Klein Hilla, die verkaufte magd, năht weinend ihre säume, die königin, ihre herrin, fragt: was weinst du, klein Hilla? Ach, ich liess mich entfuhren, und dafur verkauften mich meine eltern! Und wer hat dich denn entfuhrt? Ein ritter namens Hillebrand. Das ist ja mein sohn! Und Hillebrand heiratet seine Hilla. Ist nicht die geschichte des Hillaromans eine duodezausgabe der geschichte des romans uberhaupt?

\section{II.}

Der oberdeutsche Walther, der sg. Waltharius, nach spielmännischen vorlagen im zehnten $\mathrm{jh}$. von einem mönch lateinisch aufgezeichnet, ist ein gedicht auf Walthers kampf im Wasgenwald mit zwölf verfolgern (und ihrem könig). In 481 versen wird die vorgeschichte erzählt, dann beginnt die verfolgung und fuhrt bis v. 1443, mit 1455 endet das gedicht. Die

1) In der tat lässt sich klein Hellellild in ihres vaters abwesenheit im krieg entführen. 
zwölf zweikămpfe waren wenigstens dem vergilianischen mönch die pointe des ganzen. Der ausgang ist, dass sich Hagen und Walther grässlich verstummeln, aber der entfuhrer behält die jungfrau. Die vorangehenden elf kämpfe werden gegen sonst unbelegte recken gekämpft; es mussten eben zwölf kämpfe sein. Da noch ein dreizehnter, der könig, dabei ist, wird er im zwölften kampf Hagen gesellt und das zweikampfsystem endgultig zerbroohen; schơn die vorangehenden einzelkämpfe waren durch situationsmache kunstlich herbeigefuhrt: Walther focht am eingang einer engen schlucht. Der kern der uberlieferung ist offenbar der kampf des entfuhrers wider zwölf verfolger.

Die verfolger in dem gedicht sind Gibichungen; und da die Gibichungen kraft rheinischer Nibelungensage schatzräuber sind, so ist der grund der verfolgung ein schatz, welchen Walther den Hunen entflihrte, und den der könig Gunther als das von seinem vater an Attila gezinste gut in anspruch nimmt. Um dieser gewaltsamen motivierung gleich den bals zu brechen, verlangt Gunthers bote naturlich schatz und jungfrau: die entfuhrte, zugleich der einzige kampfpreis des Walgierz und der Hillengruppe, ist der unzureichend verhohlene gegenstand des zwölfkampfes.

Der grund der entfuhrung ist in dem gedicht die gemeinsame flucht aus dem Hunenland; von den Gibichungen zu Etzel war nur ein schritt: Walther und Hildegund waren seine geisseln, vergeisselt in zartem kindesalter von ihren zagen königlichen våtern. Sie lieben sich, sie waren schon als kinder versprochen. Als nach einem siegesmahl die Hunen auf gut spielmännisch berauscht sind, entfliehen sie auf einem ross; Hildegund mit dem schatz der königin in zwoi truhen, jenem schatz, der die Gibichungenjagd veranlassen soll, und um dessentwillen Hildegund pragmatisch als schatzmeisterin der Hunenfurstin eingefuhrt wird. Da die Gibichungenjagd pointe ist, düfen die Hunen nicht verfolgen: sie furchten sich vor Walthei, der sich bei ihnen als furchtbarer waffenheld bewăhrt hat. Verraten werden die fluchtlinge den Gibichungen durch fremde fische, mit welchen sie die Rheinuberfahrt erkaufen, und die der fährmann an die königstafel bringt: darum hat Walther gleich in der ersten fluchtberatung Hildegund be- 
auftragt von einem schmiede krumme angelhaken zu besorgen, weil sie auf der flucht von fischen und vögeln leben mussten. Der fährmann hat den schatz in den truhen klingen hören, und da der bekanntlich beldenkundige Hagen sofort weiss, dass der fluchtling Walther sei und aus dem Hunenlande komme (war er doch selbst dort einst vergeisselt und hatte mit Walther blutsfreundschaft geschlossen), so hat Gunther sein stichwort, den Hunenschatz, und die Gibichungenjagd beginnt, nicht ohne Hagen, der als eigenmann folgen muss. Natürlich begegnet dem Gibichungensänger sofort etwas menschliches: Gunther zieht nur mit zwölf recken auf die verfolgung; der zwölfkampf der tuberlieferung verlangt sein recht.

Im walde bei jener rast ereilt, welche zug um zug im schwedischen Hillalied widerkehrt, macht Walther einen sthnversuch: statt den frechen boten, der ihm gut und jungfrau abfordert, seiner wege zu weisen, bietet er goldene lösung; aber die Gibichungen wollen den schatz und die jungfrau, und der zwölfkampf hebt an. Nachdem elf verfolger erschlagen sind, wendet sich Gunther flehend an Hagen, der vergebens zu der sulhne geraten und sich dann grollend abseits gehalten hat; er sass auf seinem schild und schaute zu, citiert das Nibelungenlied die vorlage. Die mannestreue gebietet ihm den blutsbruder zu bekämpfen; das ist der vertiefte conflict, welcher die vorlage durchschimmerte und wol nur eine nachbildung des unendlich tiefer aufgefassten Rudegerconflictes war. Um Walther aus seiner schlucht zu locken, reiten Hagen und Gunther scheinbar davon, und der ermudete held, der sich nicht wie ein dieb im dunkeln davonstehlen will, rastet in stimmungsvoller nachtscene, abwechselnd mit Hildegund wachend und schlummernd. Am morgen weiterziehend, werden sie wie Walgierz im reiten uberfallen; alle werden grässlich verstummelt, am schlechtesten kommt naturlich der tritagonist Gunther weg, der dichter bewirft ihn beinah selbst mit faulen eiern. Hildegund verbindet die wunden, die blutsbrtiderschaft wird erneuert, und unter scherzreden schliesst die handlung, welche so grausig $\mathrm{zu}$ enden sich anschickte.

Genau besehen ist das ende gerade grausig genug; der eine bleibt mit einem bein, der andere mit einer hand, der dritte mit einem auge und gespaltener wange zuruck. Ein 
solcher schluss klingt unursprunglich und ist mit dem bekannten leichtsinn spielmännischer erfindung in einem so wolgofugten gedicht ubel erklärt; Hildegund mag die wunden heilen: die verlorenen gliedmassen stellt sie nicht wider her. Es ist, als ol) ein gegenseitiges schauerliches morden durchklänge, und in der tat hat man momente aufgetrieben, die auch fur die Waltheruberlieferung eine wendung mit ublem ausgang als alt tuberliefert wahrscheinlich machen könnten. Dass Hildegund in der nacht zwischen beiden kämpfen sich das wachen mit gesang vertreibt, besagt nicht viel; mehr vielleicht ihre eigenschaft als wundenverbinderin, welche an die entstellung der totenerweckung in dem schildgesang des sg. Bragi erinnert und in dem wundenverbinder Wate der Kudrun ein gegenstlick von allerdings gleich fragwürdiger altertumlichkeit hat. Der beste grund ist Walthers gebet. Rastend von dem blutigen gemetzel, fugt er die häupter der erschlagenen seufzend jedes an seinen rumpf und verrichtet dann, gen osten gewendet, vor dem entblössten schwert ein gebet - fur ihre seelen. Diese christlich gewante und doch so beidnisch angelegte, episch tief empfundene scene hat man mit den anderen angefuhrten momenten als angebliche erinnerungen an die totenerweckung durch Hilde zusammengelesen. Ihre valkyrische blutdurstige kampfstachelung aber in einen ags. Valderesplitter hinein $\mathrm{zu}$ interpretieren, ist schon weniger als unvorsichtig.

Mit bestinmtheit lässt sich sagen, dass der gegenstand der oberdeutschen Walthertberlieferung der kanpf eines entfuhrers um eine entfuhrte mit zwölf verfolgern nach vorausgegangenem subneversuch, und dass unter jenen zwölf ein Hagen war, mit dem sich der entscheidungskampf vollzog. Sein name veranlasste die association des Gibichungenmotivs, dem er kraft rheinischer Nibelungensage untrennbar zugehörte, und dieses wider hat einerseits das schatzmotiv, andrerseits das Hunenmotiv nach sich gezogen; ob auch das blutsbrudermotiv, das in der Gibichungensage eine grosse rolle spielte, ist fraglich; dasselbe kann damals auch im deutschen roman bereits schmarozt haben.

Die entstellung der burgundischen Gibichungen zu Franken fällt schwerlich dem mönch zur last; sie kehrt im Walgierz und, uberzeugender, mit der gleichen verschiebung in einem, 
an den namen Apollonius geknupften spielmannsroman der Ds. $\left.^{1}\right)$ wider: der jarl Apollonius, am Rhein von Attila eingesetzt, entführt die tochter ${ }^{2}$ ) des Frankenkönigs, an dessen landesgrenze der Waslaungwald liegt. Also die entfuhrte königstochter der Hildenvulgata (natürlich wird sie in abwesenheit des vaters entfuhrt) vermengt mit einer erinnerung an die Frankenverfolgung im Wasgenwald. ${ }^{3}$ ) Naturlich wird das motiv sofort wider fallen gelassen. Der vater heisst Salomon, folglich will die tochter eigentlich gar nichts von dem jarl wissen und wird erst durch den typischen zauberring der Salomonsage zur liebe gezwungen; auch dieses motiv wird gleich vergessen; die ganze tberlieferung ist ein ameisenhaufen von motiven.

Wenn nun ferner die von Osantrix, dem Rother der $\mathbf{p}_{\mathrm{s}}$. entfuhrte jungfrau eine tochter des Hunenkönigs ist, so wird sich niemand uber die geradezu notwendige verschiebung wundern, dass der Walther der $\mathrm{p}_{\mathbf{8}}$. von den Hunen verfolgt wird und unter diesen Hunen, also in Etzels dienst, von dem unvermeidlichen Hagen. Walther ist der neffe Ermanrichs und

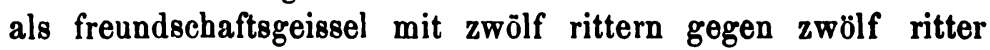
und einen neffen Attilas eingetauscht worden. Später wird den Hunen die griechische jarltochter Hildegund vergeisselt und der Hunenkönigin dienerin, das beisst wol, da sie später ihren schatz entfuhrt, schatzmeisterin. Bei einem grossen fest gestehen sie sich ihre liebe und bereden die flucht: man sieht das schlechte gedächtnis des contaminators oder seines gewährsmannes. Zwölf hunische verfolger, darunter Hagen, ereilen die fluchtigen im reiten; Walther erschlägt elf, Hagen entkommt, Walther ist schwer wund. Während die fluchtlinge abends im walde rasten und Walther einen eber siedet, bemerkt Hildegund den hinterrlicks heranschleichenden Hagen, und auf ihren warnruf rasch mit dem brustbein des ebers sich bewehrend, schlägt Walther dem Hagen ein auge aus. Nachmals versöhnt Ermanrich den Attila.

1) bs. ist bekanntlich eine willkürliche contamination niederdentscher sagenberichte aus dem 13. jh.

2) Dieselbe wird Hartung genannt: entstellt aus Helgunda? oder der name des entführers, und dann vielleicht entstellt aus Herburt?

8) Apollonius soll mit zehn bis zwölf rittern zur entfluhrung kommen. 
Im grossen ganzen stimmt diese niederdeutsche uberlieferung zug um zug zu dem oberdeutschen Walther: flucht der hunischen geisseln; zwölf verfolger, worunter ein Hagen; zwei überfälle: einmal im reiten, einmal im rasten; in einem kampf, dem ersten, elf verfolger erschlagen, der zweite ein zweikampf mit Hagen; Hagen verliert (im zweiten) ein auge, Walther wird (im ersten) schwer verwundet. Offenbar ist die Walthariusvorlage nach Niederdeutschland gewandert und bat unterwegs das rheinische Gibichungenmotiv eingebusst. In dieser uberlieferung taucht auf einmal ein neues element auf: die rast und der uberfall beim ebersieden; eine scene, zu stimmungsvoll und beinah mythisch altertumlich, um von dem geistlosen contaminator oder auch nur einem späten spielmann erfunden zu sein, und dem ritterlich modernen Gibichungenkampf schlechthin unvereinbar. Man hat trotzdem wenigstens eine erinnerung an die scene dem Walthariusoriginal imputiert und sich auf Hagens und Walthers scherzreden gestlutzt, in welchen Walther Hagens neckische aufforderung, er solle sich einen hirsch jagen und aus dessen haut eine neue rechte stopfen, mit dem hieb beantwortet: jage ich hirsche, so wirst du eberfleisch meiden! offenbar unter bezugnahme auf Hagens zahnlosigkeit; da die stelle aber aus der zähigkeit des eberfleisches erklärlich ist, so kann man doch höchstens annehmen, dass dem spielmann in folge jener alten erinnerung der neue witz eingefallen sei. Wie man dartber denke: jedenfalls belegt auch die neue version den zweikampf mit Hagen als den entscheidungskampf. $\mathrm{Ob}$ er mit Hagens einäugigkeit endete, ist sehr fraglich; noch unwahrscheinlicher, dass er der zweite akt eines doppelkampfes gewesen wäre; der doppelkampf ist ein nirgends wider auch nur erinnerungsweise auftauchendes unicum der Gibichungenversion; der Valgierz kennt nur den zweikampf, der Hillengruppe scheint der zwölfkampf zu grunde zu liegen; vielleicht combinierte aus diesen beiden versionen der Gibichungensänger seinen doppelkampf.

Der dritte niederdeutsche Waltherbeleg ist die sage von Herburt und Hilde. Die $b_{s}$. schweisst sie an ihren Dietrichcyclus an: Herburt wirbt als Dietrichs bote; bindeglied ist ein roman, der aus der werbung Alexanders fur Ludwig in den sieben weisen meistern bekannt ist und mit einer neuen feinen 
wendung in Heinrichs Apollonius auftaucht: die jungfrau fragt den werber, warum er nicht fur sich werbe (Herburt hat ihr den Dietrich verleidet $\left.{ }^{1}\right)$ ); statt aber wie Alexander dem freunde treu zu bleiben, macht es Herburt wie herr Nilaus in der nordischen ballade ${ }^{2}$ ): er nimmt die Braut für sich, er entfuhrt sie. Hier setzt die entfuhrungssage ein: der vater sendet verfolger nach; als Herburt sie sieht, steigt er ab, bindet sein ross an und macht Hilde zu seinem weib; dann erschlägt er zwölf ritter (und vierzehn knappen), reitet zu einem könig und vollführt grosse taten. Offenbar ist die brutale und widersinnige scene vor dem kampf eine entstellung der rastsituation. Also wider ein kampf und zwar ein zwölfkampf.

Von Herburt ist auch oberdeutsch gesungen worden: beinah gleichzeitig taucht er mit der bezeichnung von Tenelant im Biterolf auf. Er hat eine Hildeburg ganz allein ihren verwanten abgewonnen und entfubrt; unterwegs wird er, nachdem er den in jener phase des deutschen romans unvermeidlichen riesen getōtet, von Dietrich und Hildebrand angerannt, die ihm die vil rîche Hildeburg abnehmen wollen (also wol die jungfrau und ihren schatz), schlägt sich aber zum Rhein durch. Das land, aus dem er sie entfuhrt, ist Ormanie, ibr vater Ludwig, ibr bruder Hartmut. Man sieht, der dichter ist nicht blöde, seine abenteuer nach rechts und links anzuknupfen; Waltharius und Kudrun sind ihm gerade gut genug, einem seiner schemenhaften helden etwas ansehen umzuhängen. Immerhin weiss auch er von einer Herburtsage, die ein gutes ende nimmt und die entfuhrung einer königstochter zum gegenstand hat; die verfolgung geht von dem vater aus. ${ }^{3}$ )

\section{III.}

Die Walthersage hat uns auf niederdeutschem gebiet bereits in widerholte beruhrung mit den grossen spielmannsromanen gebracht, mit einem terrain, auf dem die motive hin und wider schwirren wie tauben in einem schlag, wo das contradictorische gegenspiel des litterarischen eigentums besteht, die armen an geist sich gegenseits um ihre paar ge-

1) Man beachte, wie die schlusspointe den verlsuf regiert!

2) Nyerup IV, $254 . \quad$ 8) Vgl. 8. 534.

Beitrăge zur geschichte der deutuchen sprache. XIV. 
danken bestehlen und fremden flitter verschiedenster herkunft um ihre blössen hängen; wo die neuigkeitssucht eines gewissen publikums so gross gefuttert war, dass auch die besseren geister alle erreichbaren uberlieferungen zusammenrafften und ibrer epen kein ende fanden. Aus einer solchen geschmacks- und schöpfungsperiode ist der grosse spielmannsroman der Kudrun herausgewachsen; wer ihn begreifen will, muss ihn zuvor im kreise seiner gattungsgenossen, der spielmannsromane des zwölften jahrhunderts, auf seinen motivenbestand hin in's augè fassen.

Das grosse spielmannggedicht auf Salman und Morolf ist fur den romanforscher eine fundgrube der belehrung. Die controle seines complicierten gefuges wird durch eine kurze, aber treffliche prosattberlieferung erleichtert, welche dem kleinen streitgedicht des Salman und Marolf nachgetragen ist, obwol sie ihm sageninhaltlich widerspricht; denn in dem streitgedicht ist Marolf Salmans gegner, in der prosa sein helfer, wenn auch nicht, wie in dem romangedicht, sein bruder.

1. In dem romangedicht dominiert das entfuhrungsmotiv ${ }^{1}$ ); also hat auch der christliche kaiser Salman seine vordem heidnische gemahlin Salme entfuhrt. Der heidenkönig Fore will sie seinerseits entfuhren (die beihalfe von Salmes vater gibt einen beigeschmack von ruckentfuhrung). 2. Fores entfuhrung vollzieht sich vermittelst eines neu associierten motives, dessen sonderexistenz Vogt in dem Rasoroman der nug. cur. nachgewiesen hat: der feindliche könig wird geschlagen, gefangen und der hut der gattin therantwortet, gewinnt ibre liebe und entflieht mit ihr. So einfach geht es freilich bei dem spielmann nicht zu; das zweite unvermeidliche motiv der Salmansage ist ein wunderbarer ring: Fore zwingt Salme durch einen zauberring zur liebe. Er entflieht auch nicht gleich mit ihr sondern erst allein und sendet ihr, um ihr zur flucht zu verhelfen, einen boten: naturlich einen spielmann. Nach der ge-

1) Es ist eine wol zu beachtende eigenschaft vieler fabulierer verschiedenster volker und zeiten, dass sie ihre pointe gleichsam tendenziös aus allen falten des romangewandes hervorschauen lassen; von modernen grössen vergl. man lbsens Stützen der gesellschaft und die bemerkungen Brandes' ther Zolas symbolik: Deutsche rundschau, januar 1888 B. $27 \mathrm{ff}$. 
naueren prosa hat sie sich krank gestellt, und der spielmann will mit seinem spiel die kranken heilen können; man vergleiche die gleich geistreichen heilsteine des rückentfuhrenden Rotherspielmanns. $\mathrm{Zu}$ ihr gelangt, steckt or ihr eine zauberwurz zu, welche sie scheintot macht, und entfuhrt sie aus dem grabe. Woher der sänger das stlicklein hat, weiss ich nicht zil sagen. 3. Bis hierher hat der buffo des gedichtes, Morolf, nur eine nebenfigur abgegeben und als warner, der der scheintoten Salme versuchsweise mit geschmolzenem metall ein loch in die hand brannte, Salmans gnade verwirkt; jetzt tritt er seine rolle an: er wird auf die suche nach Salme gesant. Nach der genaueren prosa zieht er als krämer von stadt zu stadt, bis er, vor Fores burg gelangt, unter den zu seinem kram herausströmenden frauen Salme beim handschubkauf an dem loch in der hand erkennt. 3 a. In dem gedicht kommt Morolf als waller zu Fores burg, wird von Salme erkannt, gefangen genommen und entkommt auf burleske weise (naturlich drei mal). 3 b. Nach siebenjähriger abwesenheit kommt er in seiner wallertracht unkenntlich zu Salman zurbck, wird nach Morolf gefragt, gibt sich fur tot aus, aber uber Salmans schmerz zu erkennen. Diese treuprobe des unkenntlich heimkehrenden ist offenbar dem heimkehrkreis entnommen und bei ibrem sichtlichen gemutsinbalt und dem scheinbaren fehlen des in der orientalischen wandersippe vorherrschenden erkennungsrings (einem in diesem ringsuchtigen roman nicht $\mathrm{zu}$ ubersehenden umstand) wol der einheimischen sippe zugehörig. 4. Salman rustet ein heer, fährt uber und verbirgt es im wald, geht (naturlich von Morolf veranlasst) in pilgertracht auf die burg, kommt in der genaueren prosa zu Salme, wird von ihr erkannt und Fore uberliefert. Diese einfache uberlieferung kannte der romandichter, nahm sie aber in $3 \mathrm{a}$. fur Morolfs fahrt voraus; jetzt hat er ein neues motiv in bereitschaft: 4 a. der böse entfuhrer hat eire gute schwester; zu ihr kommt Salman, und da die schlusspointe des gedichtes seine vermählung mit ihr ist, verliebt sie sich gleich jetzt in ihn und möchte ihn fur immer dabehalten. Das hindert aber nicht, dass sie zu Salme geht und ihr sagt, ein schöner pilger sei da, der wol könig Salman sein düre; wir bewegen uns eben in der periode der entartetsten spielmannspoesie, die auf ver- 
nunft und kunstlerischen anstand gleich wenig anspruch erhebt. Als die schwester sieht, dass Salme böses sinnt, möchte sie Salman warnen; aber Salme kommt ibr zuvor und lässt ihn holen. $4 \mathrm{~b}$. Fore ist gerade abwesend; dieser, wie wir sehen werden, urspritngliche zug ward wol von der kurzen prosa nur tibergangen. $4 \mathrm{c}$. Salme fuhrt Salman in ein gemach hinter einen teppich, wo er zeuge ihrer liebkosungen mit dem heimkehrenden Fore werden muss; sie erzählt demselben von Salmans ankunft und zeigt ihm sein versteck. Diese episode enthält die pointe der modification jener ursprünglichen Salmanuberlieferung: der spielmann associierte einen roman, den Vogt als orientalisches wandergut der Pantschatantrasippe nachgewiesen und, mit einer besonderen wendung, abendländisch in der chronistischen forterzählung des polnischen Walgierzromans und in einem russischen volkslied belegt hat, der also, in Russland und Deutschland wol unabhängig von einander auftauchend, vielleicht einer gemeinsamen griechischen quelle entstammt: eine frau lässt sich entfuhren; der betrogene gatte erreicht sie in abwesenheit des entfubrers, wird beschwatzt, scheinbar versteckt, dem heimkehrenden entfuhrer uberantwortet, angekettet der zeuge ihrer ehebrecherischen liebkosungen, durch die schwester des entflihrers heimlich seiner bande erledigt, erschlägt die ehebrecher und heiratet die schwester. Diese heirat ward des spielmanns schlusspointe, die schwester die intẹressante person; in alle scenen der handlung drängt er sie kunftig ein und verdirbt, verwirrt und zerstört sich seinen letzten wahrscheinlichkeitsrest. 4 d. Salme fragt Fore, was mit Salman geschehen solle; Fore ist geneigt ihn zu schonen, wenn er sich gut verantworte. Die schwester geht mit einem becher weins hinter den teppich und bittet Salman sich gut zu verantworten; sie liebt ihn ja und möchte ibn retten. Salman aber tritt zornig hervor. 5. Hier setzt wider die prosa ein und mit ihr die ursprungliche uberlieferung. Nach prosa und gedicht spricht Salman, von Fore gefragt, was er mit ihm tun wurde, mit der erwiderung: ihn hängen! sich selbst das todesurteil. 5 a. Jetzt widerholt sich 2.: der gefesselte Salman wird in die hut der guten schwester gegeben, und sie will ihn entspringen lassen; ja, es schwebte dem spielmann sogar die gemeinsame flucht vor, denn or 
associiert das Horantmotiv: Salman singt ihr zu eines spielmanns laute so schön vor, dass sie ihn noch mehr liebt und - auf ihre gefahr entkommen lassen will; das erlaubt naturlich seine ehre nicht, und der weiterverlauf des Salmanromans mit der orientalischen schlusspointe ist gerettet. Dem orientalischen roman entsprechend löst sie Salmans fesseln; da er freilich verbleibt, wird der verlauf durch diese guttat nicht modificiert. Man sieht, wie die verschiedensten motive ineinander verwoben sind. 6. Salman wird von könig, königin und volk vor den wald zur hinrichtung geleitet. 6 a. Die gute schwester reitet neben ihm und trocknet ihm den angstschweiss. 7. Er erbittet und erbält trotz Salmes widerspruch die erlaubnis, dreimal in sein horn zu stossen. $7 \mathrm{a}$. Seine schaaren sind schon sichtbar, er erklärt sie der guten schwester. 8. Beim zweiten (in der prosa beim dritten) hornstoss bricht das heer hervor. Fore wird gehängt und in der genaueren prosa Salme getötet; der romandichter aber hat noch eine fortsetzung in bereitschaft und lässt sie begnadigen; auch die vermählung mit der guten schwester wird also noch hinausgerïckt; doch wird dieselbe mitgenommen und getauft. 8 a. Das romangedicht fugt eine zweite entfuhrung der Salme an, durch einen heidenkönig Prinzian, wider mit hulfe des liebezaubernden ringes; an diesen associiert es sofort einen ringroman: Prinzian kommt als pilger und wirft Salme den (zauber-)ring in den becher; das ist der typus, $z u$ welchem der orientalische ${ }^{1}$ ) heimkebrroman sich im abendland ausgebildet hat, und den ich aus meiner geringen belesenheit allein durch funf beispiele belegen könnte. Die pointe der concurrierenden zweiten Salmanuberlieferung, welche der spielmann in 8 a. angeknlupft hat, war ein zauberring: Salman hatte ihn Salme unmittelbar vor ibrer entfuhrung durch Prinzian gegeben, er besass geheime kräfte, und es war eine torheit ihn Salme zu vertrauen; von Salme empfieng ihn der entfuhrer, von dem ihn der als bote ausgesante Morolf durch list zurlickgewinnt; Salme vermisst ibn sofort und befurchtet das schlimmste von Salman, Salman ist tiber seine widergewinnung hoch erfreut,

1) Der immer von dem einheimisch ausgebildeten streng zu scheiden ist: s. Berger, Orendel LXXX ff. 
und Morolf, der diesmal den heereszug gegen Prinzian unternimmt, vergisst nicht den ring mitzunehmen. Die eigentliche bedeutung des ringes war vielleicht schon der vorlage, sicher dem nacherzähler abhanden gekommen; er ist der ring Salomonis der talmudischen Salomonsage und das prototyp aller jener den Salmanroman durchwimmelnden ringe.

Das verhältnis der orientalischen Salomon- zur deutschen Salmansage hat Vogt uberzeugend dargetan. Ich recapituliere sein ergebnis unter wenigen modificationen, deren wichtigste ich in meinen Orendeluntersuchungen (Beitr. XIII s. 100 ff.) zu begrunden versuchte: Eine altsemitische (heidnische?) uberlieferung, nach welcher ein könig seiner sunden halber entthront und nach einer suhnezeit, während deren er bettelhaft im elend weilen musste, wider eingesetzt wird, wächst in folge biblischer therlieferungen an den sagenumwobenen Salomon an; der grund seiner entthronung (auf gottes geheiss) ist sein verkehr mit heidnischen weibern (ehe mit der tochter Pharaos), sein widersacher, der ihn sturzt, einer jener dämonen, deren bekämpfung den hauptinhalt seines sagenkreises bildet, und die er kraft eines zauberringes beherrscht; sein sturz erfolgt durch verlust, seine widererbebung durch ruckgewinnung des ringes. Der dämon, der ihn sturzt, ist in gewissen versionen der faunische Aschmedai, nach anderen, wie es scheint, ein Markulis; nach einer griechischen tberlieferung, die nach Russland gelangte, hatte der dämon die gestalt eines rossmenschen und trăgt daher in einer russischen version den

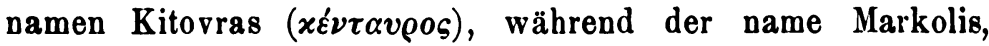
ebenfalls griechisch ubermittelt, sich in Deutschland unter angleichung an heimische namen zu Markolf, Marolf, Morolf, Morolt umbildete. Unter dem einfluss einer biblischen uberlieferung ist dieser dämon in gewissen orientalischen versionen als Salomons bruder gefasst worden, und als solcher erscheint der russische Kitovras und, zum teil, der deutsche Markolf. Ursprunglich erbält der dämon Salomons ring durch list kraft göttlicher fugung, auf dass Salomon fur seine beidnische bublsehaft gestraft werde; später ist es die buhlerische heidin, welche ihm den ring verschaff. Und wie immer ist das weib, sobald es in den roman motivierend eintritt, das alles verdrängende motiv: der ring wird vergessen, die untreue 
bleibt; der ringraub wird frauenentfuhrung. Ein entfuhrungsroman entwickelt sich, vielleicht erst auf griechischem boden; jedenfalls war es ein griechischer roman, der, in mannigfachen versionen nach Deutschland und Russland verpflanzt, auf deutschem und slavischem boden unabhängig von einander eine zug um zug ubereinstimmende Salomonuberlieferung auftauchen liess. Der entfuhrer ist jetzt naturlich ein irdischer könig ${ }^{1}$ ); ein russischer Por weist auf Porus von Indien, der deutsche Fore auf den ursprunglicheren Pharao; beide scheinen aus dem vater der heidin zu ihrem entfuhier verschoben zu sein. Der deutsche Markolf ist in dem compromiss der concurrierenden uberlieferungen vor dem siegreichen Fore in die typische, buffonischer verwendung gunstige botenrolle des brautfahrtromans ${ }^{2}$ ) zurtuckgewichen, weil er für die entfuhrerrolle nicht mehr geeignet war: als gegner Salomons ubernommen, war er sein specifischer gegner in den, der deutschen streitpoesie innerlich verwanten, salomonischen dämonendisputationen geworden und hatte sich, im contrast zu dem hochweisen Salomon und im anschluss an seine unreinliche dämonennatur als schlauer und unflätiger bauer gefasst, zu dem ideal eines grobspielmännischen buffo ausgebildet.

In dem russischen roman, welcher in so auffallender weise mit der deutschen Salmanuberlieferung ubereinstimmt, ist ein kaiser Vasilj der intellectuelle entfuhrer. Er sendet einen boten in krämerverkleidung, der die schöne Salamanija durch köstliche geschenke auf sein schiff lockt, (bewirtet, berauscht) und entfuhrt. Als Salomon von der entfuhrung hört, sammelt er ein beer gefligelter rossmenschen, erteilt ihnen die weisung, wenn sie ihn zum ersten mal sein horn blasen hören, sollen sie satteln, beim zweiten hornruf aufsitzen, beim dritten zu hulfe eilen, zieht als pilger (bettler) uber meer, kommt in abwesenbeit des kaisers zur kaiserin, wird erkannt (bewirtet, berauscht, in eine kiste gesperrt) und dem heimkehrenden kaiser uberliefert. In einer version wählt er sich selbst den tod durch bängen, erbittet und erhält trotz einspruch der frau die erlaubnis (drei mal)

i) Nur Kitovras hat seine dämonische natur bewahrt.

2) จ. Oswalds raben. 
zu blasen, das heer kommt, der kaiser, sein bote und Salamanija werden gehängt. In eine prosa ist ein zug des orientalischen heimkehrromans eingewachsen: der pilger Salomon erbittet sich von einem mädchen den goldnen becher der kaiserin, mit dem sie gerade wasser schöpft, zum trinken und lässt seinen ring hineinfallen wie der Moringer im volkslied. An dem ring wird er erkannt.

Salomon als pilger der entfürten Salamanija nachziebend, von ihr erkannt, dem heimkehrenden entfuhrer überantwortet, sich selbst die todesart wählend, die gnade des hornrufes wider einspruch der entfuhrten erbaltend, auf den dritten hornruf von dem heere befreit, entfuhrer und entfübrte tötend - diesem identitätsbeweis muss nan sich ergeben. Das krämermotiv ist von dem boten des entfuhrers auf den boten des rlickentfubrers ubergegangen; dass es in dem griechischdeutschen original an der nämlichen stelle stand, beweist ein zweites deutsches spielmannsgedicht, welches denselben roman benutzt hat: der könig Rother.

Die pointe der an Rothers namen geknüpften uberlieferung war die befreiung seiner liebesboten, eingekleidet in die abliche brautfahrtsfabel. Rother kommt unter fremdem namen als geächteter und lenkt durch seine riesisch buffonische begleitung die aufmerksamkeit der königstochter auf sich, so dass sie ihn zu seben verlangt. Wie er bei ihr und mit den gefangenen an's ziel kommt, hat ein dichter mit anmutiger erfindung erzählt, ein stumper armselig nachgereimt und um folgende handlung erweitert ${ }^{1}$ ): während Rother in kriege abwesend ist, schickt der vater der entfuhrten einen boten, naturlich einen spielmann, in krämerverkleidung mit köstlichen geschmeiden und gewändern. Statt die neugier der königin durch geschenke zu reizen, bedient er sich einer mit echt spielmännischer albernheit neu erfundenen list: er gibt kiesel fur wundersteine aus, welche, von einer königin berlihrt, beilkräftig wider jedes gebresten wurden; doch miisse die berührung auf seinem schiffe stattfinden. Einer so feinen falle

1) Dass die Rothervorlage mit dem ersten teil endete, ergibt sich aus der correspondierenden Osantrixüberlieferung der $b_{s}$. und aus dem versiechen aller dichterischen originalität in dem zweiten teil (mit ausnahme der eingeflochtenen heimkehrsituation). 
kann die königin nicht entgeben und wird entfubrt. Rother, bei seiner rlickkehr unterrichtet, eilt mit einem heere nach, birgt es hinter berg und wald und geht als waller in die stadt. Vom waller zur heimkehrscene ist nicht weit. Seine gattin hält gerade hochzeit mit einem feindlichen kōnigssohn; er schleicht sich (mit zwei begleitern) in den hochzeitssaal, duckt sich in sehr wahrscheinlicher weise unter den tisch und steckt ibr den erkennungsring zu. Sie lächelt vor freude, und sehr hubsch ist es, wie sich ibr trauriger vater mit diesem lächeln freut; der vater des bräutigams aber schöpt verdacht: Du hast kunde von Rother! Die turren werden verstanden, und nach einer beratung unter dem tisch schlupft Rother hervor. Nun ist der spielmann wider im alten geleis; Rother wăhlt sich selbst den tod durch hăngen, er wird von allen hinausgefubrt, erbittet zwar nicht die erlaubnis zu blasen sondern wird von leuten, denen er wolgetan, befreit, ein anderer bläst für ihn, das heer bricht hervor, und der - bubler wird gehängt. Alles in allem eine dem zusammenhang nach genauere widergabe des griechisch-deutschen romans, pointiert zu einer rückentfuhrung und untermischt mit heimkehrmotiven.

Das krämermotiv kehrt im Oswald wider. Die 0swaldsage hat Berger erledigt: an die legende von dem christenkönig, der, an der bekehrung eines heidenkönigs beteiligt, dessen tochter heiratet, knupfte ein spielmann die brautfahrt nach der beidentochter im anschluss an die Hildenvulgata: entfuhrung in abwesenheit des vaters, verfolgung und einholung auf der insel, erschlagung aller heiden, (wunderbare) widererweckung und, in einer version, erneuter kampf. Die abwesenheit ist eine abwesenheit auf der jagd; die jagd wird echt spielmännisch mit einem listiger weise vergoldeten hirsch begründet; darum erscheinen die entfuhrer, in dem kleinen gedichte richtig als kaufleute eingefuhrt, in dem grossen als goldschmiede. Auch das horn ist nicht vergessen; nur bläst nicht der gatte sondern der vater der entfuhrten mit ihm seine mannen zusammen. $\mathrm{Zu}$ bemerken ist 1. die verwendung der kaufmannslist als einer weise der Hildenentführung, 2. dass der entfuhrer selbst, nicht sein bote, die maske trägt. 
Der brautfahrt des Orendel, welche ebenfalls Berger orledigt hat, liegt eine heimkehrsage zu grund. Der spielmann kannte drei ${ }^{1}$ ) versionen. Die erste, $A$, stand noch mit einem fuss auf mythischem gebiet und wusste von riesischer buhlschaft, welche der dichter nach dem kunstgesetz der drei guten dinge in drei sich steigernden riesenkämpfen bis zu einer machtvollen spannung in die höhe trieb; die beiden andern, B 1 und B 2, stehen völlig auf concretem boden und wissen nur von einem buhler, der ein irdischer könig ist. Der könig von $B 1$ hat die treue Bride einem peiniger ubergeben, dessen peinigungen nach der legende schmecken; in B 1 kann er, so gut er in den heimkehrkreis passt, nicht ursprunglich sein, da die straffe situation, in welcher B 1 gipfelt, ein plötzliches und schnelles erscheinen der Bride erfordert und durch den aufschub ihrer entkerkerung und bekleidung geradezu gesprengt wärde; vielleicht gehört der zug nach B 2, das mit B 1 durch einander geraten und unvollständig berichtet ist.

Der ursprlungliche bestand von B 1 ist kaum aus der uberlieferung heraus zu schälen. Orendel kommt, wie es scheint, mit einem begleiter, zu seiner burg und findet einen torwart. Dass er ibn an seinem gebet als christen erkennt, gehört in die legendenbearbeitung; $\mathrm{da}$ er in seiner pilgertracht unkenntlich und nicht in Palăstina ist, bedarf er auch nicht im voraus einer sicherstellung. Der torwart, ein alter, măchtiger recke, mit schönen zugen geschildert, nimmt die fremden gastlich auf, bewirtet sie und befragt sie nach ihrer herkunft; es ist wol echt, dass sie sich als entronnene heidengefangene, also aus dem osten, dem Orient, heimkebrende pilger ausgeben. Nicht echt ist, dass er sie bittet, wenn sie nach Ackers kămen, seinem herrn Orendel Brides gefangenschaft zu vermelden; echt ist jedenfalls, dass er ihnen die leiden seiner herrin klagt. Bei der vortrefflichkeit der vorlage kann hierauf nicht nuchtern und abrupt die erkennung erfolgt sein; sie wird in ruhrender weise, an diese treuprobe anknupfend, ein- und durchgefuhrt worden sein; ein beispiel solcher ruhrenden erkennungsscenen haben wir im Morolfgedicht gefunden. Es scheint, dass der begleiter ein verwanter des torwartes war.

1) Nach Berger nur zwei; auch das folgende stimmt nicht liberall zu seinen ausfuhrungen. 
Die darauf folgende dramatische hauptscene des gedichtes wird mit hullfe eines heeres gelöst, welches Orendel, ehe er mit seinem begleiter als pilger auf botschaft gieng, im geröhr verborgen hatte; als or sein bedarf, beruft es in der legende eine himmelstaube, in dem original des motivs bestimmt der hornruf. Ich gestehe, dass ich des heeres nicht zu entraten wltsste. Der könig ist in den turm geflohen, Orendel steht vor der pforte, des königs mannen sturmen herbei. Er zaudert: soll er die pforte wahren oder sich auf die mannen sturzen? Da tritt Bride mit gezogenem schwert hinzu: habe keine sorge, hier kommt keiner ein noch aus! diese scene als moment eines kampfes, zu dem Orendel in das horn gestossen hat und von aussen seine mannen herantoben, während er von innen wurgt und Bride den könig im turm bewacht, erscheint mir grossartig, aber ohne diese cooperation von aussen und innen Orendels sieg undenkbar. Der kōnig war vielleicht als ein erobernder furst vermenschlicht?

Auch in B 2 bat Orendel ein heer bei sich; er liegt, wie es scheint, vor der stadt rerborgen und hat Bride botschaft gesant. Der könig begehrt ibre minne, lässt sich einen schlaftrunk bringen, der ihn bewåltigt, wird von einem treuen mann getötet, welcher Bride wappnet, worauf sie den turhutter erschlägt und Orendel in die stadt lässt. Man möge mich nicht fur einen phantasten verketzern, wenn ich diesen bericht dahin zu entwirren suche, dass die vielleicht misshandelte Bride, darch botschaft von Orendels ankunft unterrichtet, sich gegen den vergewaltiger willig stellt, worauf ihm etwa der treue diener den schlaftrunk reicht und sich das weitere wie in dem gedicht abspielt.

\section{IV.}

Vergegenwărtigen wir uns noch einmal unsern sagengeschichtlichen befund der Hildentberlieferung: In der nordischen sippe wird dem Dänenkōnig. Högni während seiner abwesenheit (zuweilen im krieg) von einem norwegischen viking Hedin seine tochter Hildr entfuhrt; in der fremde oder nach seiner ruckkehr unterrichtet, verfolgt und ereilt er den răuber auf einer insel; ein versöhnungsversuch vor dem kampf oder in einer kampfpause scheitert an Högnis zorn; der kampf, welcher 
heer gegen heer oder als zweikampf statt findet, geht in ewigkeit fort oder wird von den erschlagenen fortgekämpft, die nach einer wendung von Hildr hierzu durch zauberlieder erweckt werden. Bei Saxo fällt in einer uberlieferung der entfuhrer; die mit dieser wendung gegebene rechtsentscheidung zu seinen ungunsten tritt in $\mathrm{S}$. D. wie ein directes schuldverdict zu tage. An diese wendung wächst der im norden zum typus ausgebildete holmgang der nebenbuhler an: dem verfolgenden vater gesellt die Shetlandsballade den von ihm beglinstigten bewerber; und da die pointe der ballade Hildinas rache ist, so wird 1. der vater als unwesentlich bei seite geschoben (er wäre ohne die ränke des nebenbullers zur versöhnung geneigt) und der nebenbuhler der rächer der entfuhrung, 2. der verfolgende nebenbuhler als gewalttätiger bösewicht aufgefasst, der unterliegende entfuhrer als der heissgeliebte. Der kampfplatz ist das reich des entfuhrers. Zur zeit der entfuhrung sind der vater und der von ihm begünstigte bewerber im krieg. In der polnischen Walgierzuberlieferung ist der verfolger wider der ungeliebte, (wie es scheint, von dem vater) begunstigte, der entfuhrer der geliebte bewerber; da er aber Walther heisst, folgt die zum typus gewordene wendung der Walthersage: er erschlägt den verfolger.

Die sg. Walthersage ist eine Hildensage, die von Walther und Herburt gesungen wurde; von wem ursprunglich, ist fraglich; doch klingt die alliterierende verknupfung Herburt Hilde, also des liebenden und der geliebten, ursprlunglicher als die von Walther - Wasgenstein: dem helden und seiner typischen tat. Eigentümliche zlige sind 1. der binnenländische charakter: die fluchtigen werden im reiten oder auf der rast ereilt, 2. die in einer wendung durchgedrungene zwölfzahl der verfolger, 3. der zum mindesten durchgedrungene sieg des entfuhrers (hinter dem man spuren eines altecht uberlieferten wechselmordes hat finden wollen). Mit der nordischen vulgata stimmt u. a. der im Waltharius erhaltene versöhnungsversuch. Im Waltharius ist der kampf ein doppelkampf von fraglicher ursprunglichkeit; die entscheidung fällt im kampf mit Hagen, einem ursprlingliehen zweikampf, welcher vielleicht mit dem zwölfkampf zu jenem doppelkampf combiniert wurde.

Man hat die theorie aufgestellt, dass die Walthersage die 
selbständige deutsche ausbildung eines pangermanischen Hildenmythus sei. Hierfur spricht zweierlei ${ }^{1}$ ): 1 . ist durch $\mathbf{b}_{\mathbf{s}}$. eine altertumliche uberlieferung erhalten, nach der Hagen den entfuhrer (nachts) auf der rast beim ebersieden hinterrucks uberfällt und aufs Hildes warnruf von ihm mit einem eberknochen ein auge ausgeschlagen erbält (ursprünglich: erschlagen wird?); eine situation, in ihrer altpoetischen ursprunglichkeit so wirkungsvoll, dass sie leicht den rastuberfall als binnenländisches gegenstück des nordischen bolmgangs zum typus erheben konnte; 2. ist die verknupfung der Walthersage mit dem Gibichungenmotiv, mag sie auch kecker spielmannswillkür entsprungen sein und einer zeitlich uberwiegenden beliebtheit dieses motivs innerhalb der romanfabulierung ihr dasein und ihr überwinden zu danken haben, schwer vereinbar mit einer uberlieferung, welche Hagen als Hildes vater kannte, und könnte als rest einer ursprünglicheren tradition etwas von einer riesischen vergewaltigerrolle Hagens bewahrt haben; vielleicht wäre aus einer derartigen tradition auch das motiv der (zwölf?) wächter zu erklären. Man sieht, die frage ist nicht mehr auf sagengeschichtlichem boden zu entscheiden.

Bleibt die westgermanische originalität der Walthersage sonach eine offene frage, so ist die nordische herkunft der um den namen Kudrun gereihten Hildenuberlieferungen ausser zweifel. Beweis ist schon die namengebung: Hetel ist Hedin, Hagen Högni (uber Horant wird später gehandelt werden); auch die form Kudrun erklärt sich aus nordischer uberwanderung, obzwar sie, auf keinen anderen namen der sage alliterierend, erst secundär in die uberlieferung eingedrungen sein durfte; Judwig als entfuhrer steht nur nordisch in alliteration zu Hilde und, gesetzt den fall einer alten prägung der formel Ludwig und Hartmut, zu Hartmut. Der kampf auf dem Wulpenwert hat endlich den nordischen holmgang bewahrt.

Das Kudrungedicht ist in der vorliegenden gestalt das product einer fragwurdigen vorgeschichte. Es ist sicher, dass eine formal uberarbeitende hand aus liebe zum reimgeklingel viele strophen entstellt (vielleicht auch manche hinzugefugt) hat; sicher, dass ein interpolator, dem die Nibelungenstrophe

1) Die eigentiimlichkeit des ausgangs ist natlirlich ohne beweiskraft. 
geläufiger war, allerlei vermeintliche verfeinerungen eingeflickt hat, wobei es ihm einmal widerfährt, dass or aus schlechtem gedächtnis oder abweichender sagenkenntnis im gegensatz zu dem gesammten gedichtinhalt Hartmut als Kudruns entfuhrer bezeichnet. Unangesehen diese sichtlichen neuerungen, uberbleibt ein ausgesponnener roman, dessen verlauf durch widersprüche und unwahrscheinlichkeiten beeinträchtigt wird; die rollen Fruotes und Horants sind anfänglich nicht klar auseinandergehalten; Ludwig und Hartmut fliessen in ihrer gemeinsamen entfuhrertätigkeit häufig in einander, so dass urheber und helfer sich nicht immer abheben und bald der eine bald der andere den nebenspieler drlickt; wenn Kudrun bei ihrer ankunft in Ormanie Gerlind den kuss verweigert als der urheberin ihres unglückes, so möchte man auf die unurspringlichkeit dieser kenntnis des unbekannten schwören, und alles, was sich um die gute schwester des bösen entfuhrers dreht, ist so schemenhaft und so lose eingeknupft, dass die lebhaftesten zweifel an der altechten zugehörigkeit dieser persönlichkeit nur natürlich sind. Ob aber alle diese unebenheiten späteren uberarbeiterhănden zuzuweisen sind, ist eine erst zu erledigende frage.

Die kritiker der Kudrun scheinen von der annahme auszugehn, dass das original von 1210 ein gutes gedicht (was sie unter einem guten gedicht verstehn) gewesen sei. Wenn sie demgemäss als merkmal späterer uberarbeitung verschiedenheiten im ton zu constatieren suchen, so ist das ein unanfechtbares verfahren; gefährlicher schon ist das operieren mit widerspruchen, denn was verburgt uns, dass nicht der verfasser sich durch die kenntnis mehrerer, abweichender traditionen, die er zu vereinbaren trachtete, verwirren liess und, bald der einen, bald der anderen ein ubergewicht einräumend, bisweilen mit den eigenen angaben in widerspruch geriet? Während sich immerhin auch für dieses kriterium einzelne, wol unanfechtbare belege beibringen lassen, ist das dritte der weitschweifigkeiten beinahe unzulässig; derartige merkmale berechtigen zu kritischen ausscheidungen nur durch ihr sporadisches abweichen von dem gesammtcharakter der uberlieferung. Die frage nach dem gesammtcharakter ist die grundfrage der kritik. 
Das Kudrungedicht, wie es vorliegt, ist ein ausgesponnener roman von zwei hervortretenden eigentumlichkeiten: einmal einer neigung zu reichlicher breite in schilderung und dialogen, sodann dem bestreben nach allseitiger kunstlerischer verkntipfung. Gesetzt den fall, es war im wesentlichen eines mannes werk, so war dies ein mann von vielem kunstgefuhl, dem das motivieren am herzen lag. Er beginnt den roman ab ovo und führt ihn zu möglichst vollständigem abschluss; er knüpft jeden faden bei zeiten an und lässt ihn nicht wider fallen. Der raub der Kudrun geschieht, während der vater und der begünstigte bewerber im krieg sind: mit wem kämpfen sie? mit einem abgewiesenen bewerber Sigfrid; die bewerbung desselben wird vor der doppelwerbung Hartmuts und Herwigs eingefubrt; als die entfubrung der Kudrun zur schlichtung des krieges fuhrt, schliesst sich Sigfrid den verfolgern an, und auch dem rachezug nach Ormanie darf er nicht fehlen. Der verfolgende vater fällt auf dem Wulpenwert: warum unterliegt die gerechte sache? weil die verfolger heilige pilger ihrer schiffe beraubt haben; dieselben werden ihnen später zur stlbne zurtckgegeben. Hetel ist heiratslustig; warum? er ist eine waise, hat weder vater noch mutter! Die epische situation ist, dass Herwig und sein gefährte Kudrun mit einer jungfrau beim waschen finden: nicht allein, dass diese letztere gesellung (allerdings unter verdächtiger vorausnahme eines spăteren motivs) vorgefubrt wird, die gesellte jungfrau ist auch jene Hildeburg von Portugal, welche der schönen Hilde von Irland nachfolgte, ja, eine der drei greifenjungfrauen der eingangserzählung. Für den dichter oder redactor sind Ludwig und Gerlind bősewichte; das kunstgesetz des contrastes verlangt also, dass ihr sohn Hartmut gut und edelsinnig sei. Kudrun will ihm eigentlich auch recht wol; sie hat ihm sogar, als er, von liebe getrieben, unerkannt an ihren hof kam und ihr allein seine anwesenheit entdeckte, raten lassen sein leben in sicherheit $\mathrm{zu}$ bringen (allerdings eine recht unanschauliche situation). Warum wird uberhaupt seine werbung unumstösslich abgelehnt? weil sein vater von Kudruns grossvater lehen empfieng. Das verhältnis der guten alten lieder hat sich umgekehrt: jetzt gilt die motivierung alles und die situation nichts. 
Eine ähnliche kunstlerische eigentumlichkeit zeigt $X$, wie ich diese hypothetische persönlichkeit nennen will, bei der behandlung der, ihm zahlreich genug uberlieferten und vielleicht von ihm noch vermehrten helden der dichtung. Wie in dem personenreichen drama eines neulings machen die vielen recken, die alle eines gewissen spielraums bedurfen, einander wind und sonne streitig; $\mathrm{X}$ ist augenscheinlich bemuht einem jeden gerecht zu werden. Man betrachte den entscheidungskampf in Ormanie. Die helden sind alle rachebedürftig; erst läuft Ortwin, das kind, Hartmut an und wird verwundet; dann kommt Horant gesturmt, als ob alles sturzen und brechen solle, aber Hartmuts stunde ist noch nicht gekommen, und auch er wird verwundet; dazwischen wurde beschrieben, wie Herwig und andre helden fochten, und jetzt folgt in breiter und prachtvoller ausfthrung das hauptstück der entscheidung: Herwig erschlägt Ludwig; hinterdrein die minder wichtige uberwindung Hartmuts durch Wate. Jeder muss sein teil haben; da für den sagenbertihmten Horant in dem entscheidungskampf kein rechter raum ist, erhält er von Hilde mit der fahne eine art erste fuhrerschaft. Was hat man nicht alles aus solchen zugen folgern wollen!

Diesen beobachtungen entspricht, dass $\mathrm{X}$ in der schon einmal charakterisierten weise vieler fabulierer seine hauptmotive an allen enden des romans zum vorschein bringt. Sein stoff ist eine Hildensage: folglich heisst Hagens frau Hilde, seine tochter: Hilde, Gudruns treue begleiterin und deren treuloses gegenstuck sind wider Hilden. Gegenstand des gedichtes ist der kampf um eine jungfrau: darum ist Herwigs werbung um die jungfrau ein kampf und Sigfrids kampf eine folge seiner werbung um die jungfrau.

Derartige eigentumlichkeiten geben dem gedicht das aussehen eines zur einheit verarbeiteten werkes, und ich glaube, wir haben kein recht diese einheit als das nachträgliche, successive werk mehrerer $X$ anzunehmen, so lange nicht stilistische unterschiede diese annahme aufdrängen. Solche unterschiede sind nur insofern vorhanden, als, gleichsam unter der oberfläche, durch das ganze gedicht hin charakteristische details urspringlicherer färbung in verschicdener dichtigkeit der häufung verstreut sind. Am spärlichsten in der jugend- 
geschichte Hagens, die bei einer gewissen freundlichen naivität der schilderung physiognomielos und dichterisch arm ist; die liebliche strophe 111) steht beinah verlassen in solcher umgebung. Auch was von Hagens vermählung, seiner tochter Hilde und Hetels werbeabsichten erzählt wird, ist reizlos und wenig eindringlich, bis mit Wates einfuhrung plötzlich farbe in das gewebe kommt und, ohne dass der stil sich änderte, charakteristische einzelheiten und episoden älterer prågung auftauchen. Als gänzlich unvermittelt und uberraschend in die kaufmännische reckenwerbung Horants gesang hineinschneit, ertönt eine ganz neue seite ron einer seit str. 11 nicht mehr vernommenen lieblichkeit. Dann folgen in der entfuhrung Hildes einige charakteristische striche, in dem verfolgungskampf ein paar markante zlige, immer ohne dass die erzăhlungsweise sich ändert; nur der poetische gehalt ist an solchen stellen grösser und von älterer färbung. Eine wüstenei conventioneller armseligkeit vermittelt zu der teilweise vortrefflich dialogisierten entfuhrungsscene der Kudrun, an welche sich in Hildes botschaft und Hetels klage einzelne volle und starke töne schliessen; die verfolgung ist von ödester umständlichkeit, und inmitten breit und uberflussig detaillierter heldenkämpfen wird das hauptstlick des inselkampfs: Hetel wird von Ludwig erschlagen, in einer strophe berichtet. Folgt kurz und markant die scheidung des kampfes und das nächtliche entweichen der räuber; auch der heimkehr fehlen nicht ein paar altechte tõne. Dies alles aber ist umwoben von einem wust von nebensächlichkeiten, in der regel beherrscht von pragmatischen und dramatischen bedurfnissen der verknupfung und rollendurchfubrung.

Die orzăhlung geht zunächst in der charakterisierten weise weiter: lange farblose fäden durchwoben mit kurzen farbenhaltigen. Doch werden die letzteren entschieden dichter. Kudruns leiden bei Gerlind sind tiefcharakteristisch, die sich dazwischen schiebenden unterredungen Hartmuts vielfach ausgesponnen und verworren; jene haben die ubliche dreizahl der steigerung, diese werden durch die episode der guten schwester des argen entfuhrers vermehrfacht. Da beginnt der rachezug der Hege-

1) Ich citiere nach Symons.

Beltrăge zur geschiohte der dentechen sprache. XIV. 
lingen, erst conventionell, leer, bis zu der situation, wo Herwig und sein begleiter auf botschaft gehen und die waschenden jungfrauen tinden, und mit einem schlag ist das verhältnis ein anderes: das charakteristische überwiegt, die herrlichste poesie flutet dahin, die convention ist in den Acheron versunken. So geht es bis zu den kampfscenen; hier wollen wider die einzelnen helden zu ihrem recht kommen; aber der prächtige kampf Herwigs und Ludwigs, manche ztlge von Hartmuts heldentum und die scharf umrissene bestrafung Gerlinds durch Wate sind von unverkennbarer altechtheit. Und damit ist das treffliche zu ende; was folgt, ist conventionell und dem gesammtton entsprechend.

Gesetzt, das vorliegende gedicht ist im grossen ganzen das werk eines $\mathrm{X}$, gedichtet unter benutzung alterer gedichte, so sind die alten elemente in der partie von Kudruns rückentfuhrung von einer dermassen einzigen dichtigkeit, dass notwendig als die eigentliche vorlage des $\mathrm{X}$ ein gedicht auf diese zurtuckfuhrung anzunehmen ist, anhebend mit der knapp berichteten entfubrung, meldung, klage, verfolgung (das hauptstuck des inselkampfs in einer strophe), uber die reichlicher geschilderte leidenszeit gelangend $\mathrm{zu}$ der breit ausgemalten widergewinnung: der pointe des gedichtes, welche bewirkte, dass in dem inselkampf der verfolgende vater fiel und diesmal der begunstigte nebenbuhler der bei seite geschobene mitverfolger wurde, der auf die scblussaction aufgespart blieb. Um diesen kern hătte dann $X$ seinen grossen roman unter benutzung weiterer Hildenlieder gedichtet. Fur diese auffassung sprechen zwei beoachtungen: 1 . die vulgata der Hildensage, der holmgang um die von einem norwegischen viking in kriegerischer abwesenheit des vaters entfuhrte tochter Hildr eines Dånenkönigs, bildet die ausgangshandlung jenes als eigentliche vorlage isolierten ruckfthrungsromans, nur dass der norwegische viking ein heerender Normanne geworden und das nebenbuhlermotiv eingewachsen ist; und in der folge kann in der vorgeschweissten Hildenentfuhrung der vater nicht mehr Dåne sein, weil ja der entfubrer Dăne ist als kunftiger vater der eigentlichen entfuhrten, und der kampf ist nicht mehr inselkampf sondern ein kampf in dem lande des entfuhrers. 2. was an dem tuberkommenen gedicht ursprtinglich ist, ob 
viel, ob wenig, kann kunstgeschichtlich nicht vor etwa dem jahre 1200 verfasst sein; da nun hundert jahre fruher bereits auf oberdeutschem boden eine complicierte Hildenuberlieferung bestand, aus welcher uns die namen Wolfenwert, Hagen, Herwig, Wate, Wolfwin (fur Ortwin irrtumlich in folge des Wolfenwertes?), Horant, Kudrun belegt sind, ftur die damalige kunstweise aber die annahme complicierter spielmannsromane anhaltslos wăre, diejenige einfacher lieder durch die nachgewiesenen Orendeloriginale empirisch gedeckt ist, so hat man sich in derartigen liedern die Hildensage mit mannich fachen wendungen und ausgestaltungen als im sängermund oberdeutsch lebendig vorzustellen, bis aus ihnen ein dichter von den umfassenden gestaltungstendenzen des Orendelspielmanns einen grossen roman schuf. Mehr als splitter jener lieder wird aus diesem auch das schärfste forscherauge nicht - erraten können.

Auf diesen standpunkt gestellt, hat der sagenforscher nunmehr die frage zu erheben: welche darstellung gab $X$ von der Hildensage?

Hagen, typisch der wilde genannt, auch vâlant aller künige, hat eine tochter Hilde. Viele umwerben sie; aber die uberbringer der werbung mussen ${ }^{1}$ ) ihre sendung mit dem leben bezahlen. $\mathrm{Zu}$ jener zeit gedenkt der măchtige Hetel sich zu vermăhlen; Morunc nennt ihm Hilde, und da die werbung gefährlich ist, răt er Horants rat einzuholen. Dass Morunc Horants berufung veranlasst, ist charakteristisch; sie erscheinen in dem Hildenkapitel verknupft und werden widerholt hintereinander eingefuhrt.2) Mit Horant kommt Fruote, gern der kubne genannt, obwol er als der besonnene geprägt ist. Auf seinen rat wird der alte Wate, der ze Sturmen sitzt, so zu sagen der buffo des gedichtes, berufen: wider sebr charakteristisch, denn Wate und Fruote erscheinen fortan in formelhafter verknupfung. Sie sind in der tat die eigentlichen boten: Wate vertritt die gewalt, Fruote die list. Fruote zieht

1) Vielleicht eine pragmatische vorausnahme.

2) Str. 271/2, 332/3, 394, 488/9,711/12; in 310 steht in für diese stelle verdächtiger weise für Morunc Irolt. Ueber die anordnung zu zweien, such im Orendel, s. u. 
als kaufmann mit kostbarem krame, in den schiffsbäuchen verborgen lauern Wates krieger. Horant hat eigentlich nichts bei der fahrt zu tun; ihn notdürftig einzuflechten, wird er anfänglich von Fruote für die krämerrolle in aussicht genommen. Sie schlagen ihren kram auf, die burger strömen aus Hagens stadt. Hagen gewährt ihnen seinen frieden, zum dank (man beachte die feine motivierung) senden sie ihm köstliche geschenke, und diese geschenke erregen die aufmerksamkeit von mutter und tochter. Zu erwarten wäre nun als logischer verlauf, dass die also erweckte neugier die frauen an bord lockte und die entfuhrung durch die verborgenen krieger bewerkstelligt warde; aber der motivschatz des dichters ist noch nicht erschöpft. Die fremden sind nicht allein kaufleute, sie kommen zugleich in recken wise als geächtete wie Rother, und wie Rother erregen sie durch ihren bufforiesen Wate die aufmerksamkeit der königstochter, dass sie den wunsch ausspricht die merkwürdigen fremden zu seben. Das fuhrt zu allerlei burlesken scenen, aber natürlich der entscheidung um keinen schritt näher. Da greift, diesmal gänzlich unerwartet und ohne jede organische einknlipfung, ein neues motiv ein: eines abends singt Horant so schön, dass die vöglein lauschend verstummen und die königstochter staunend lauscht. Mit tagesanbruch singt er ${ }^{1}$ ) abermals, dass die vögel der lieder vergessen und die junge Hilde ihren vater bittet den sänger zu hofe - kommen zu lassen? aber er ist ja bei hofe; sie bittet also den sănger bei hofe singen zu lassen. Und der vater lehnt die bitte ab; er muss sie ablehnen, damit die dritte, entscheidende stufe erreicht wird: Horant singt zum dritten male, und diesmal halten die tiere des waldes auf der weide, die würmer im kriechen, die vöglein im fliegen inne, und die königstochter widersteht nicht lănger und lăsst den sănger heimlich in ihr gemach. Damit ist die situation der uberlieferung gegeben: Horant in Moruncs begleitung als heimlicher liebeswerber bei Hilde. Was aber ist das resultat dieser werbung? Hilde willigt in die flucht, dergestalt, dass sie uber der besichtigung der schätze auf dem schiffent-

1) Wol auf der burgzinne an des wächters stelle? 
fuhrt wird. Zu diesem endergebnis hätte es natturlich der ganzen episode nicht bedurft. In der tberkommenen fassung schliesst sich eine kleine interessante scene an: der oberkämmerer uberrascht die fremden in Hildes gemach, es stellt sich aber heraus, dass er ein fluchtiger verwanter Horants ist, sie feiern ein widersehen unter tränen, und er bringt die männer mit listen von dannen. Die gemutliche einschaltung stammt wol aus dem scenarium der heimkehrsagen.

Der kern dieser entfuhrung ist also die kaufmannslist, und wahrscheinlich deren ursprtingliche gestalt die verlockung der jungfrau zu schiff durch ihre neugier erregende köstliche geschenke. Diese wendung erschien wol dem höfisch gebildeten spielmann nicht wahrscheinlich, und er modernisierte sie mit hülfe des geächtetenmotivs in der Rotherprägung und der selbständigen, ebenfalls geprăgten sangeswerbung Horants. Träger dieser entfuhrung sind typisch verbunden Wate und Fruote. Naturlich ist die kaufmannslist auf die Hildensage nur angewendet; bereits hier sei darauf hin gewiesen, dass sie in der ursprunglich erscheinenden gestalt genau der entfuhrung der Salamanija entspricht; zu derselben stimmt auch die in der Hildenuberlieferung beispiellose wendung einer entfuhrung durch boten.

Diese wendung allein schon benötigt die verlegung des holmgangs auf Hetels gebiet ${ }^{1}$ ), der nunmehr selbst in die vulgatarolle des entfuhrers eintritt. In dem 2 weikampf gegen Hagen unterliegt er augenscheinlich; selbst der ebenburtige Wate, der ihn abløst, empfängt von dem wilden eine schwere wunde, gerăt aber nun in solche wut, dass es am ende Hagen doch ubel ergangen wäre, wenn nicht auf Hildes flehen Hetel, den bedurfnissen des weiteren verlaufs entsprechend, den kampf geschieden hätte. Naturlich ist Hagen zur versöhnung geneigt, Wate heilt die wunden, und alles löst sich in frieden und freundschaft. Mehr als den entscheidungszweikampf Hagens und Hetels mit einer durchschimmernden tradition von Hetels erliegen wird diesem ausgang kein vorsichtiger sagenforscher als altuberlieferte zuge entnehmen durfen.

Hilde und Hetel gewinnen in Dänemark eine tochter. Sie

1) Motiviert: Hagens schiffe waren nicht gleich verfolgungstichtig. 
ist wider schön, viel nmworben und verweigert. Unter ihren bewerbern treten zwei hervor: der eine, Herwig, gewinnt durch tapferkeit des vaters gunst und der tochter hand, der andere, der Normanne Hartmut, wird verschmăht. Wăhrend einmal der vater und der begunstigte im krieg sind, heert der verschmähte Normanne (mit seinem vater) in Dänemark und ent. fuhrt die tochter. Der vater, in der fremde durch boten be. nachrichtigt, setzt mit dem begunstigten den räubern nach, ereilt sie auf einer insel, dem Wulpenwert, und fällt (gegen den vater des räubers).

Die nacht unterbricht den kampf; die räuber benutzen sie, mit ihrer beute zu entkommen. Der vorsprung, den sie gewinnen, war zu gross um sie zu verfolgen, motiviert der dichter; aber das urspringliche kommt bei der heimkehr zu Hilde zum vorschein: Wate tritt traurig vor die königin: alle deine mannen sind erschlagen. So muss die entfuhrte Kudrun in den händen ihrer räuber bleiben, bis eine neue streitbare jugend erwachsen ist, und es ist raum fur ihre leidenszeit und wahrscheinlichkeit für die seltsamkeiten ihrer widergewinnung gewonnen.

Kudrun ist in den händen eines buhlerischen bewerbers; es kostet sie ein wort, eine herrscherin $z u$ werden, sie aber bleibt dem fernen gatten treu und leidet. Hartmut hat nămlich eine mutter, deren laster ibre ubergrosse liebe zu dem sobn ist. Sie hasst das weib, das nicht ihrem sohn zu eigen werden will, wie sie es lieben wurde, wenn es ihm willfahrte. Durch misshandlungen sucht sie seinen stolz zu brechen: nun muost du eiten minen phiesel und muost schluren selbe die brende! und die arme Kudrun ist willig zu gehorchen: iedoch hât vil selten miner muoter tohter geschurt die brende! nie ist der volkston schöner angestimmt worden; die worte klingen wie Faladas seufzer: wenn das deine mutter wlusste, das herz in leibe wurd' ihr zerspringen. Die zweite stufe von Kudruns qual ist, dass sie feuern und kehren und mit ihren haaren schemel und bänke wischen muss; immer fuhlt man sich im bereiche der märchen von der argen stiefmutter und dem armen mägdlein, dessen schönheit asche und elend nicht zuzudecken vermögen, bis der strahlende königssobn sie findet und erlöst. Ueber der dritten, bärtesten prufung erscheint der 
erlöser: in schnee und eis, im bitterlichen winter muss die arme königstochter im meere wäsche spulen; und siehe da, wie sie und die treue jungfrau am gestade stehen, baarfuss, in ihren nassen, blossen hemdlein zitternd vor kälte, kommen in einem kahn $z$ wei fremde junglinge geschwommen; schamvoll wollen sie fliehen, aber der eine, der jungere, ruft den schōnen wäscherinnen scherzend nach und droht ihnen ihre wäsche zu rauben; zögernd kehren sie um, und wen finden sie? ibre befreier, ihre retter, den gemahl und als seinen gefährten den (sicher ursprünglich) mittlerweile herangewachsenen jungen bruder.

$X$ gibt dem verlauf der ereignisse die wendung, dass ein engel den waschenden frauen die nahenden retter verkundet; auch sonst hat er die situation durch eine zu starke hervorarbeitung der bruderrolle, welche den gatten drückt, in der klarbeit geschădigt; aber die eigentliche widererkennungsscene stellt sofort das rechte verhältnis her: Herwig ist die bauptperson, Ortwin der begleiter. Und in der tat spielt Ortwin nirgends eine entscheidende rolle: Herwig erschlägt den mōrder von Ortwins vater.

Die Hegelinge haben endlich die befreiungsfahrt gerustet, zu der naturlich alle jemals aufgetretenen helden (mit ausnahme des unmöglichen Hagen, der mit seiner vaterrolle ausgespielt hat) versammelt werden. Das heer landet verborgen hinter wald und berg, Herwig geht mit Ortwin a uf botschaft; der abschied ist so tränenvoll, als giengen sie in pilgertracht auf Ludwigs burg. Sie kehren aber nach dem widersehen mit der entfubrtengattin, die ja ein treues weib ist, zurluck, und Wate als der älteste macht nun den befehlshaber: wir lagern uns uber nacht vor der burg; mit dem morgengrauen stosse ich dreimal in mein horn; beim ersten zeichen rustet ibr euch, beim zweiten sat telt die pferde, beim dritten sitzt gewaffnet auf. Später, wie das hornsignal wirklich erfolgt (nachdem die feinde längst alarmiert sind), wird die reihenfolge der wirkung etwas abweichend angegeben: beim ersten hornstoss eilen die Hegelinge zu den zeichen, beim zweiten sitzen sie auf, beim dritten brechen sie auf. Naturlich hat das bornmotiv nur einen sinn, wenn die Hegelinge noch im versteck liegen, und dann 
steht offenbar die richtige, $\mathrm{X}$ nicht sicher erinnerliche reibenfolge in der mitte seiner beiden versionen: erster stoss satteln, zweiter aufsitzen, dritter herbeieilen. Diese reibenfolge aber stimmt genau zu der hornwirkung der russischgriechischen Salomonversion und muss bei dieser detailierten tubereinstimmung unmittelbar dem griechisch-deutschen roman entnommen sein, denn nunmehr behaupte ich mit aller bestimmtheit, dass auch fur die kaufmannslist des Hildencapitels dieser viel beliebte roman die quelle des $\mathrm{X}$ abgab, und dass $X$ die alte lösung, die verlockung durch köstliche geschenke, nur unvollkommen mit den Watespässen des reckenmotivs und der ritterlich gewendeten sangeswerbung Horants zugedeckt hat.1) Herwigs fahrt nach der entfuhrten gattin hat also farben und formen der Salomonsage angenommen.

Der befreiungskampf wird mit vollem heldenapparat in scene gesetzt; die eigentliche entscheidung bildet der grandiose, mit altechter wechselrede eingefuhrte zweikampf Herwigs und Ludwigs. Man hat anstoss genommen, dass nicht Herwig den eigentlichen entfuhrer Hartmut bekămpfe und der mörderische Ludwig den răcherhănden von Hetels eigenmann Wate uberbleibe. Die uberlieferung musse verwirrt sein, und zwar verworren durch das ineinandergeraten oder gar die contamination zweier versionen oder gar gedichte, deren eines den tod des vaters durch Ludwig und die blutrache des sohnes oder eigenmannes, deren anderes die entfubrung der jungfrau durch Hartmut und ihre widergewinnung durch Herwig enthalten habe. Dieser theorie steht von vornherein entgegen, dass der bluträcher des vaters ganz allein der sohn sein konnte, welcher in dem gedicht nur eine begleiterrolle spielt, sodann, dass das gedicht uberhaupt nichts von einer blutrache weiss sondern nur von der befreiung der geraubten Kudrun, ja, endlich, dass fur einen derartigen rachezug weder aus dem Hildekreis noch aus dem damaligen roman uberhaupt sich ein empirisch beweiskräftiges analogon erbringen lässt. In der

1) Dieser zweite ubereinstimmungspunkt verbietet, einen ursprünglicheren Morolf als mittler anzunehmen. Dass der entsprechende teil des Rother unmittelbar auf den roman zurïckgreift, ist oben dargetan worden. Mit der möglichkeit eines verloren gegangenen mittelglieds kann man natürlich sich nicht befassen, 
tat wird Ludwig von Herwig nicht als Hetels mörder sondern als der entfuhrer seiner gattin erschlagen. Die auffassung des gedichtes ist, dass Ludwig und Hartmut gemeinsam ') die entfubrung unternehmen, jener, der vater, fur diesen, den sohn, jener der harte und grausame, dieser der gute und freundliche ${ }^{2}$ ); der gute, als der sturmisch liebende, veranlasst die entfuhrung, der böse befleckt die hände mit dem blute des vaters und wird schon dadurch zum subnopfer prädestiniert. Nun ist es ja richtig, dass derartige genealogische verknupfungen gewöhnlich ihre vorgeschichte haben, und es ist vielleicht sogar wahrscheinlich, dass auch $\mathrm{X}$ zwei in der tiberlieferung concurrierende entführer in compromiss versetzte oder bereits verwachsen ubernahm; aber von dieser einfachen, viel belegten annahme $\mathrm{zu}$ jener durch keinen beleg unterstutzten intuitivtheorie ist ein weiter abstand.

Dem geduldigen forscherauge enthullt sich ein organischer entwickelungsgang. Die Hildenfabel von dem kampf um die entfubrte jungfrau trug von anbeginn in sich einen starken keim der romanfortbildung. Eine solche fortbildung vollzieht sich in der wenig impulsiven litteratursphäre der volkspoesio nicht sowol vermöge activer neuerfindungen als der association benachbarter motive. So gesellte dem holmgang um die jungfrau sich der holmgang der nebenbuhler, und wie denn immer das neue motiv verhängnisvoll für die künftigen schicksale der romanfortbildung wird, so trat in den vordergrund des interesses der gegensatz der beiden liebhaber: der eine ward der entfubrer, der andere als der verfolger dem vater gesellt. In demjenigen roman, nach dessen wendung die tochter sich gern entfubren liess (Shetlandsballade), trat der verfolgende nebenbubler bereits in dem holmgang in den vordergrund: er erschlug den entfuhrer (und verfiel dann der rache der liebenden entf(uhrten); in der Kudrundichtung, in welcher die tochter

1) Für die vorliebe des gedichtes zu paarungen v. das verfolgerpaar Hetel und Herwig, die botenpaare Wate Fruote, Horant Morunc, Herwig Ortwin, das wäscherinnenpaar Kudrun Hildburg. Hierzu v. deutsch die durchgehenden paarungen des Orendelgedichtes und nordisch die unvermeidlichen paarungen Saxos.

2) v. die nämliche contrastcharakteristik an dem freierpaar der ersten Qrendelheimkehr. 
mit gewalt von dem ungeliebten entfuhrt wird, wuchs der entfuhrung das damals beliebte ruckentfuhrungsmotiv an, der verfolgende geliebte nebenbuhler ward fur die schlusspointe aufgespart und trat den entscheidenden zweikampf des holmganges an den somit hauptverfolgenden vater $a b$, der gemäss der beherrschenden schlusspointe unterliegen musste.

Gemäss dem herrschend gewordenen ruckfuhrungsmotiv ist Kudrun als gattin Herwigs entfuhrt. Die situation der ruckentfuhrung der wider willen entfuhrten treuen gattin nimmt nun von selbst die gestalt an, dass die treue gattin des fernen Herwig ron einem bublerischen vergewaltiger zur minne gezwungen werden soll. Da erscheint der ersehnte gatle - und sie erkennt ihn nicht (es sind ja so viele jahre vergangen); sie hört aber, wie er seinen begleiter mit ihres bruders namen nennt, und zitternd bei den gedanken, dass der angeredete in der tat ihr bruder sei, spricht sie ron Kudrun und gibt sie fur gestorben aus. Da weinen die beiden fremden bitterlich, und die arme Kudrun fragt - man hört ihre stimme beben - ibr weint ja, als wärt ihr Kudrun verwant! und nun existiert niemand mehr als gattin und gatte, der bruder, der so oft in der uberlieferung das grosse wort fuhrte, ist aus der situation entschwunden, und Herwig antwortet: wol weine ich um sie, denn sie war meine gattin! und was erwidert Kudrun? lhr wollt mich täuschen, Herwig ist ja tot! da kann der dichter seine heimkehrstinmung nicht mehr verhalten: Herwig holt den erkennungsring hervor, und lachend und weinend sinkt sein weib an seine brust.

Zum uberfluss ist uns die scene in ibrer ursprlinglichen heimkehrgestalt als flickwerk des Morolfgedichtes bekannt: Morolf kommt nach siebenjåhriger abwesenheit unkenntlich in pilgertracht heim zu seinem bruder, erzählt, nach Morolf befragt, von Morolfs tod und gibt sich dem weinenden bruder zu erkennen. Es ist die klasse ruhrender erkennuñ gssscenen, zu welcher die torwartscene der zweiten Orendelvorlage und die kämmererscene des Hildencapitels gehören. Die fahrt zu der umbuhlten gattin hat sich mit hulfe des heimkehrscenariums gestaltet; ob in dasselbe auch das verräterische lächeln der Kudrun, das in der ruckkehrscene des Rothergedichtes widerkehrt, das peinigermotiv, das in die zweite Orendel- 
vorlage eingang fand, und die erbeuchelte willfährigkeit, die ich in der dritten finden möchte, zu zählen sind, bleibt eine offene frage.

Das gedicht schliesst mit der bestrafung der Gerlind und mehrfachen heiraten: der gute Hartmut wird durch die gute Hildeburg entschädigt, die gute schwester Ortrun mit dem jungen bruder Ortwin belohnt. Der dichter ist ein gewissenhafter mann und lässt kein fädchen unverknotet. Sein werk ist ein roman, gedichtet auf und um die ruckentfuhrung der Kudrun. Die rtickentfuhrung ist eine fortbildung des, um das nebenbuhlermotiv bereicherten Hildenentfuhrungsromanes unter mitwirkung des fremden Salomon- und des einheimischen heimkehrromans.

Die erörterung der Hildensage gestaltete sich, wie jede sagenerörterung, als die erforschung eines romankreises, mithin als ein beitrag zur geschichte wie psychologie des (deutschen) romanes, beträchtlich für die litteraturgeschichte wie fur eine empirische poetik. Sie beleuchtete zugleich die zeitliche vorherrschaft gewisser einheimischer wie fremder stoffund motivwelten, zugleich die natur und bedeutung der fabulierung; dort bereicherte sie tatsachen, hier erhellte sie gesetze ${ }^{1}$ ); und was der einen wissenschaft $\mathrm{zu}$ gute kam, förderte die andere. Man wird noch dazu kommen die sagengeschichte so entschieden von der mythologie zu lösen, wie man die mythik aus dem bereiche der poetik entfernen wird. Als ausgangspunkt vieler deutschen romane ist freilich der mythus auch dem litterarhistoriker von belang; denn indem der mythus einem gemutsmoment (der bedeutung einer unbegriffenen naturerscheinung fur die menschliche existenz) sein dasein verdankt, trägt er bercits in sich den treibenden keim der fabulierung ${ }^{2}$ ); und das fabulieren ist der erste taumelnde kinderschritt der phantasie auf dem gebiete epischer schöpfung.

1) Besonders drei gesetze: a) über die fortbildung vermittelst der association benachbarter motive, b) über die vorwärtswirkende herrschaft des neuen motivs, c) über die riickwirkende herrschaft der schlusspointe: alle drei gesetze der passiven phantasietätigkeit, die ja auch in der kunst der activen beständig an die hand geht.

2) Das gemütsmoment allein beherrscht die passive, und vornehmlich auch die active phantasietätigkeit. 
Ueber den mythus von Hedin und Hildr wage ich hier nur nachtragsweise und in andeutungen zu handeln. $\mathrm{Zu}$ vörderst wären eingehende untersuchungen an den namen Hildr zu knupfen, die dartun möchten, dass dieser name ebensowenig ursprunglich kampf bedeutete wie der name Hulda die holde, dass vielmebr beide vor ihrer umdeutung unter einander und zu Hel und den Huldren im verhältnis standen und die bedeutung eines hehlenden wolkenwesens mit den valkyrjen und allen totengottheiteu uberhaupt und zum teil mit der vanin Freya gemein hatten.

Der kern des mythus scheint ein kampf gewesen zu sein, jener kampf, der sich dann als holmgang localisierte, als der zweikampf des beleidigten vaters mit dem entfuhrer seiner tochter oder als zweikampf der nebenbuhler. Und zwar scheint der mythus einen immer widerkehrenden kampf gekannt zu haben, mit oder ohne periodischen charakter der widerkebr; eine anschauung, welche mit der vermenschlichung der fabel, um nicht widersinnig zu werden, entarten musste und als fortkampf der erschlagenen aufgefasst wurde unter associierung eines benachbarten motivs; denn die anschauung von den nächtlicherweile den kampf fortsetzenden gefallenen ist sehr verschiedenenorts zu belegen: das bekannteste beispiel ist der catalaunische Hunenkampf. Dieser seelenkampf in den luften ist, wie es scheint, seinerseits eine entartung indogermanischer wettermythen von erbitterten luftkämpfen der götter und dämonen, und zwar eine naheliegende entartung, indem schon frubzeitig sturm- und seelenmythen sich associiert zu haben scheinen, insofern die seele an dem hauch begriffen wurde und in ihm von den windwolken kam und zu ihnen zurlickkehrte. Es ist bekannt, dass gewisse in der luft streitende dämonenschaaren direct als seelen aufgefasst wurden.

Schon vor diesem wandel durch die vermenschlichung scheint der dämonenkampf, wol noch in indogermanischer zeit, die motivierte gestalt des kampfes um eine jungfrau angenommen zu haben. Der mythische inhalt dieser letzteren wesenheit mag in verschiedenen zeiten und gegenden ein verschiedener gewesen sein, wie denn alle der mythisierung unter- 
liegenden naturvorgänge, besonders des athmosphärischèn bereiches, an allen beruhrungspunkten in einander uberfliessen; auf germanischem boden hat eine gruppe der kampfsagen eine ausgesprochen jahreszeitliche bedeutung ${ }^{1}$ ) gewonnen. Dass auch der Hildenkampf ein kampf von göttern und dämonen war, beweist eine namengebung: der eine gegner, Hedin, heisst des Hjarrandi sohn, Hjarrandi ist ein Odinname; die vorgeschichte dieser genealogischen verknlipfung, welche als eine mythische nach den erfahrungen der mythologie unursprunglich sein muss, kōnnen wir aus unserem uberlieferungsbestand entnehmen: auch an Hjarrandi knlipfte sich eine Hildenuberlieferung; Hjarrandis lied ist nordisch belegt, Heorrendas gesang taucht ags. schon im achten jahrhundert auf, und wol einem ags. sänger wurde auf niederdeutschem und später oberdeutschem gebiet die sangeswerbung eines Horant ${ }^{2}$ ) um Hilde naclgesungen, die, an einen anderen namen geknlipft, in gleicher prägung bei einem polnischen chronisten und, als physiognomieloser wandertypus, in dem Morolfgedicht, bei Saxo und Heinrich von Neustadt widerkehrt. Die werbung durch gesang braucht dem mythus nicht alteigen, kann eine durchgedrungene spielmannswendung gewesen sein, aber eine werbung Horants um Hilde wird die anerkennung des mythologen erheischen und unter die werbungsmythik zu reihen sein, welche, unter anderen von Freyr und Odin erzählt, auf sagenboden den herrlichsten mythenroman, den Sigfridroman getrieben hat.

Erst nach der erledigung der werbungsmythik und ihres sagenkreises wird sich die motivierung des Hildenkampfes durch eine Hildenentfuhrung aufklären lassen. Die deutsche mythik ist reich an entfuhrungsfabeln von einem bestimmten charakter: sie drehen sich um die entfürung einer fur die

1) Dass auch der germanischen mythik die auffassung athmosphärischer vorgänge als kampferscheinungen alteigentümlich war, ergibt sich aus noch lange fortbestehenden sprachlichen niederschlägen; . die bekannten skaldischen ausdrücke für kampf: wetter oder sturm der Hjadninge, platzregen der Hildr; waffen feuerbrände der Hjadninge; schwert feuer der Hildr; schild wolke der Hildr.

2) Daher mag sich die auffallende namenform erklären, welche ein gegenstuck $z \mathfrak{u}$ der undeutschen namengebung Kudrun bildet. 
athmosphärische befruchtung belangreichen göttin durch einen riesen wahbrend der winterlichen abwesenheit Thors und ihre zurtickerlangung durch den mit dem lenz heimkehrenden Thor. Besonders besungen als entfuhrte scheint die Vanin Freya zu sein. Wenn ich nun in betracht ziehe 1. den namen Thorhildr, 2. die innere wesensbeziehung, die zwischen Freya und Hildr bestanden haben muss und in jener uberlieferung von einem auch Hildr zuständigen halsband einen ausdruck findet, 3. den eigentumlichen zug, dass Hildr stets in abwesenheit ihres vaters entfuhrt wird, so scheinen mir diese beobachtungen folgende theorie nahe zu legen: Der mythische kampf um eine jungfrau, vielleicht schon um eine Hildr, bedeute er was er wolle, ergänzte sich motivierend vermittelst des benachbarten entfuhrungsmythus: der kampf fand statt um eine entfuhrte Hildr und bewahrte die erinnerung, dass die entfuhrung in abwesenheit einer persönlichkeit stattfand, die zu der entfuhrten in einem schätzenden verhältnis stand. Indem nun im bereich der jahreszeitlichen mythik die entfuhrung stets mit der situation begann, dass die jungfrau bereits in den händen des riesen war, und die handlung enthielt, dass sie ihm entrissen wurde, gestaltete sich, unangesehen den Hildenkreis, auf nordischem boden die auch indisch nachweisbare auffassung, dass die jungfrau nicht in die hände der riesen erst gekommen sondern ihnen $\mathrm{zu}$ eigen, eines riesen tochter war (oder auch seine gattin, seine kebse); und diese jungfrau ward dann nicht befreit sondern erworben ${ }^{1}$ ); wobei der jahreszeitliche gott auch in der unkenntlichen entstellung seiner winterlichen verbannung erschien. Dem entsprechend ist es zu begreifen, dass Hildr als Högnis tochter und Hjarrandi als ibr entfuhrer und werber auftritt; und wenn der entfuhrer auch Heð̈inn, der mit fellen bekleidete, heisst, so enthălt dieser name vielleicht die erinnerung an jene entstellung des heimkehrenden jahreszeitengottes. Und nun wird es auch anderen als ein pikanter zufall erscheinen, dass dem verfasser von Sp. aus einer mythischen erinnerung heraus der werbende und entfuhrende Hedin als ein aus dem winterland im fruhjahr erscheinender mythenheld sich gestaltete.

1) Die bekanntesten beispiele sind Gerdr und Rindr. 
Meine theorie ist also: der Hildenkampf, ein indogermanischer athmosphărischer ${ }^{1}$ ) mythus von noch unaufgeklärter bedeutung, motivierte sich aus benachbarten jahreszeitlichen entfuhrungstiberlieferungen, und diese motivierten sich aus benachbarten (jahreszeitlichen?) brautwerbungstuberlieferungen. Es sind also seitens des mythologen behufs klarstellung des Hildenmythus zu untersuchen und verfolgen: 1. die kampfmythen, besonders die von dem kampf um die jungfrau, 2. die seelenkampfmythen, mittelst deren sich jene auf dem sagengebiet fortfabulierten, 3. die entfuhrungsmythen, mit denen sich die kampfmythen fortfabulierten, 4. die werbungsmythen, vermittelst deren die entfuhrungsmythen sich weiterfabulierten. Unter den letzteren spielen die Hildensagen des Sigfridkreises eine grosse rolle, und ich will auch hier eine theoretische anschauung gestehen: unsere uberkommene, schwer lösbare sagengestalt der Sigfridmythik erklärt sicb durch das eindringen des in einer bestimmten zeit die meisten fabeln umbildenden blutsbrudermotives: der held Sigfrid, der nach, in eddischen wanderuberlieferungen bewahrten wendungen die jungfrau Hildr oder Sigrdrifa oder wie sie sonst hiess für sich selbst erwarb, warb in der späteren wendung um sie für einen schwächeren blutsfreund; denn überall in der blutsfreundschaft blieb auf die dauer die contrastcharakteristik nicht aus: war der eine der held, so war der andere der schwache, und der erste war notwendig der helfer des zweiten. Indem nun beide uberlieferungen zusammenwanderten und der erwerber der Hildr dann noch einmal, unter mitwirkung eines vergessenheitstrankes, die nämliche Hildr einem blutsfreund erwarb und dafur mit dessen schwester belohnt wurde, erwuchs die motivierung fur Sigfrids tod durch Hagen: die beleidigte Hildr verlangte ihn. Und dann blieb natürlich mit der zeit das schlusscapitel nicht aus: die gattin Sigfrids răchte seinen tod. So wird aus differenzierten, zusammengewanderten und im compromiss verglichenen werbungsfabeln unter mitwirkung vieler anderer, besonders auch historischer momente der Nibelungenroman, in dem schatz-, drachen-, riesen- und zwerg-

1) Unter dieser bezeichnung fasse ich immer alle in der athmosphäre sich abspielenden mythen zusammen. 
mythen mit brautwerbung und blutsbruderschaft zu einem grossen ganzen zuisammenflossen.

Auch uber Hagens persōnlichkeit in der Hildensage wird man vielleicht nach erledigung des Sigfridkreises zu entscheiden befähigt sein. ${ }^{1}$ ) Dass hinter ihm ein inhalt von physiognomischen gepräge stand, dafür könnte die dänische tradition von seiner riesischen erscheinung und jener deutsche originelle uberfall beim ebersieden sprechen.

Und nunmehr, nach kenntnisnahme dieses zu bewältigenden umfassenden litterar- wie mythengeschichtlichen materials, wird man vielleicht geneigt sein, für meine klihnheit, mit einer skizze vor die wissenschaftliche welt zu treten, mir absolution zu gewähren.

1) Ich mø̋chte hier bemerken, dass Müllenhoffs forderung, auf grund des nrd. Hogni einen deutschen Haguno für Hagen vorauszusetzen, für die Nibelungensage nicht zwingend ist, da der nordische sänger, seine weise einem deutschen ablauschend, einen ähnlichen einheimischen namen eingesetzt haben dürfte.

WIEN, december 1888.

LUDWIG BEER. 